\title{
Nontechnical Issues in Waste Management: Ethical, Institutional, and Political Concerns
}

May 1978

Prepared for the

U.S. Department of Energy

under Contract EY-76-C-06-1830

\section{Battelle}


NOTICE

This report was prepared as an account of work sponsored by the United States Covernment. Neither ine Linited States nor the Department of Energy, nor any of their employees, nor any of their contractori. subcontraciors, or their employees, makes any warranty, express or imolied, or assumes any legat liasility or responsibility for the accuracy. completeness or usefulness of any information, apparatus, producr or process disclosed, or represents that its use would not infringe privately owned rights.

The views, opinions and conclusions contained in this report are thote of tha contracior and do thot necestarily represent thuse of the United States Government or the United States Department af Energy.

\author{
PACIFIC NORTHWEST LABORATORY \\ operaied by \\ BATTELLE \\ for the \\ UNITED STATES DEPARTMENT OF ENERGY \\ Under Contract EY-76-C-06-7830
}

\begin{tabular}{|c|c|c|}
\hline \multicolumn{3}{|c|}{$\begin{array}{l}\text { Printed is the Un ted States of Amer } \\
\text { Avaihbie from } \\
\text { Nutional Technical Intermation Servi } \\
\text { Lrited 5tates Depirtment of Comme } \\
5285 \text { Port Roval Rood } \\
\text { Springfieid, Virginia } 22151\end{array}$} \\
\hline ce: & Printed Coo & 5. Mictofict \\
\hline & -Pages & $\begin{array}{c}\text { NTIS } \\
\text { Selling Price }\end{array}$ \\
\hline & $001-025$ & 54.50 \\
\hline & $026-053$ & $\$ 5.00$ \\
\hline & $051-075$ & 55.50 \\
\hline & $076-109)$ & 560 \\
\hline & $107-125$ & 36.50 \\
\hline & $125 \cdot 150$, & $\$ 7.00$ \\
\hline & $151-173$ & 5775 \\
\hline & $176-200$ & 5850 \\
\hline & $201 \cdot .225$ & 38.75 \\
\hline & $276-200$ & $\$ 9 . .00$ \\
\hline & $251-25$ & $510 . \mathrm{m} n$ \\
\hline & $276-100$ & $\$ 10.25$ \\
\hline
\end{tabular}


NONTECHNICAL ISSUES IN WASTE MANAGEMENT:

ETHICAL, INSTITUTIONAL, AND POLITICAL CONCERNS

by

J. A. Hébert

W. L. Rankin

P. G. Brown

C. R. Schuller

R. F. Smith

J. A. Goodnight

H. E. Lippek

May 1978

\section{BATTELLE}

Human Affairs Research Centers

Battelle Pacific Northwest Division

Seattle, Washington 98105 
4 


\section{CONTENTS}

I : INTRODUCTION

I I: ISSUES RELEVANT TO COMMERCIAL NUCLEAR WASTE MANAGEMENT • • 3

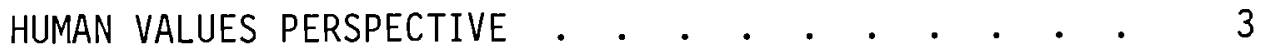

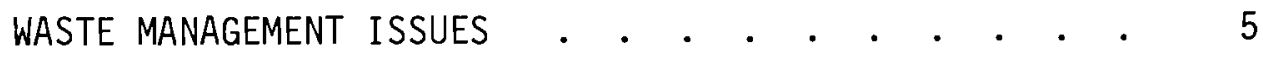

Dislocation of Costs and/or Benefits to

Future Generations . . . . . . . . 6

Need for Candor . . . . . . . . . . . 8

Public Involvement . . . . . . . . . . 10

Uncertainty . . . . . . . . . . . . 11

Risk and Equity Issues . . . . . . . . . 13

Safeguards and Civil Liberties . . . . . 15

Conservation and Alternative Power Production . 17

Transportation. . . . . . . . . . . 18

Institutional Issues . . . . . . . . . . 18

Irreversible Decisions . . . . . . . . 20

Commercial versus Defense Wastes . . . . . . 21

International Responsibilities Regarding Waste $\quad 21$

Costs of Waste Management . . . . . . . 22

CONCLUSION • . • . . . . . . . . . . . . .

FOOTNOTES • . . . . . . . . . . . . . . . . 24

III: SOME ETHICAL CONSIDERATIONS REGARDING RADIOACTIVE WASTE
DISPOSAL ISSUES..
.

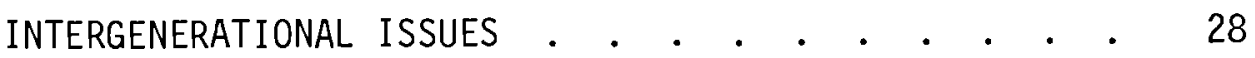

INTERGENERATIONAL PRINCIPLES . . . • . • • . • .

INTRAGENERATIONAL ISSUES . • . • • • • • • • 36

Management Problems . . . . . . . . . 37

Insurance . . . . . . . . . . . . 37 
Tort Liability System . . . . . . . . 38

Source of Reparation . . . . . . . . . . 38

Dislocation Issues . . . . . . . . . . . 38

Civil Rights Issues . . . . . . . . . . 39

Distribution of Wealth Internationally . . . 40

Other Issues . . . . . . . . . . . . . 40

FOOTNOTES • . . . . . . . . . . . . . . . . 41

IV: INSTITUTIONS IN LONG-TERM NUCLEAR WASTE MANAGEMENT • • • 43

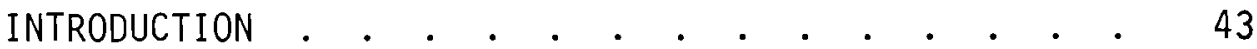

BACKGROUND . . . . . . . . . . . . . . . . . . . 44

Public Concerns . . . . . . . . . . . 44

General Characteristics of Waste Management . . 45

A FRAMEWORK FOR EXAMINING THE PROBLEM OF INSTITUTIONS

IN LONG-TERM MANAGEMENT . . . . . . . . . . . . 47

Functions that Might Be Performed . . . . 47

Time Period . . . . . . . . . . . . 48

Perceived Need for Functions . . . . . . . 48

Likelihood of Performance . . . . . . . 48

CONSIDERATIONS IN THE THREE TIME. PERIODS . . . . . 50

Phase 1 (0 to 100 Years) . . . . . . 50

Phase 2 (100 to 700 Years). . . . . . . . 55

Phase 3 (700 Years and Beyond) . . . . . 58

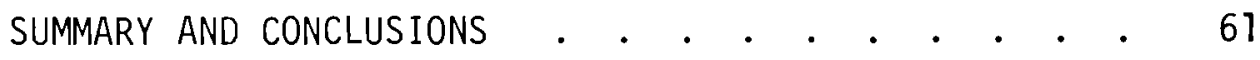

FOOTNOTES . . . . . . . . . . . . . . . 63

$V: \quad$ SHORT-TERM INSTITUTIONAL ISSUES IN NUCLEAR WASTE MANAGEMENT

INTRODUCTION . . . . . . . . . . . . . . 65

Criteria for Choosing among Alternative

Institutional Arrangements . . . . . . . 65 
Organizational Questions . . . . . . . 66

Dimensions of Waste Management . . . . . . 67

THE MANAGEMENT FUNCTION . . . . . . . . . . . . 69

Vertical Integration of Waste Management . . $\quad 69$

Organizational Options for Waste Management . . 71

THE REGULATORY FUNCTION • • • • • • • • • . • 76

Criteria for Sound Regulation . . . . . . 76

Regulatory Tasks . . . . . . . . . . . 76

Institutional Alternatives . . . . . . . . . 79

THE RESEARCH AND DEVELOPMENT FUNCTION . . . . . . 80

THE STATUS QUO IN THE WASTE MANAGEMENT SYSTEM • • •

Current Institutional Arrangements for

Management . . . . . . . . . . . 80

Current Institutional Arrangements for

Regulation . . . . . . . . . . . . 82

SUMMARY . . . . . . . . . . . . . . . . 83

FOOTNOTES . . . . . . . . . . . . . . . . . . 84

VI: GENERAL ISSUES OF INTERGOVERNMENTAL RELATIONS IN NUCLEAR

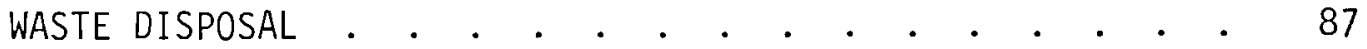

OVERVIEW . . . . . . . . . . . . . . . . . 8

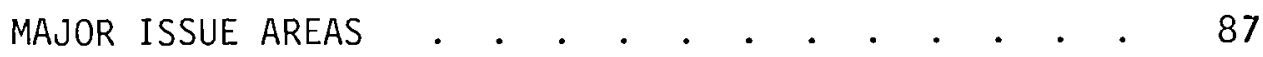

Extent of Federal Preemption of State

Authority . . . . . . . . . . . 87

Land Use Management and Energy Facility
Siting Regulations . . . . . . . . . . 88

Construction Standards . . . . . . . . 89

Transportation Management . • . . . . . 89

Environmental Standard Setting and

Monitoring . . . . . . . . . . . . 89

Emergency Preparedness Planning . . . . . 89

FEDERAL PREEMPTION POWER AND STATE ACTIVITIES • • 90 
STATE PARTICIPATION IN DECISION MAKING . . . . . 93

CONSTRUCTION STANDARDS . . . . . . . . . . . . . . 94

RELATIONSHIP OF LAND USE MANAGEMENT ISSUES TO

ALTERNATIVES FOR NUCLEAR WASTE MANAGEMENT . . . . 95

TRANSPORTATION OF RADIOACTIVE WASTE MATERIALS . • . 96

STATE PARTICIPATION IN STANDARD SETTING AND

ENVIRONMENTAL MONITORING . . . . . . . . . . . . . . . . 99

EMERGENCY PREPAREDNESS AND ACCIDENT ISSUES . . . . 101

LOCAL GOVERNMENT ACTIVITIES RELATED TO WASTE

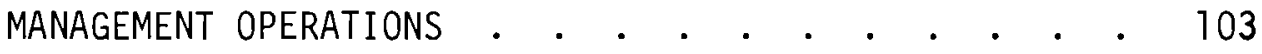

SUMMARY . . . . . . . . . . . . . . . . 103

FOOTNOTES . . . . . . . . . . . . . . . 104 


\section{CHAPTER I}

\section{INTRODUCTION}

The management and disposal of nuclear waste is seen by many as a unique problem in modern technology, largely because of the extremely long time period and potential hazard involved. This perception gives rise to both technical and nontechnical concerns about feasibility. This report focuses on the nontechnical concerns in the management of commercialiy produced nuclear waste. The aim of the report is not to draw conclusions about these issues, but to (a) present problems and concerns relating to these issues, (b) 117 uminate and probe these issues using appropriate analytical frameworks, and (c) permit readers to draw their own informed conclusions.

Much of the concern about nuclear waste management may stem from the potential dislocation of benefits and costs over generations and across groups in the current generation. Many people are looking for assurances that the risks transferred across time and places will be reasonably low. Cost-benefit analyses, never ideal within a short time frame, seem an especially weak technique for assessing concerns over long time periods because of the need to express, in today's terms, future values of benefits and costs (i.e., to find the "appropriate" discount factor--either positive or negative). Since the importance of information may be unrelated to its quantifiability, there is clearly a strong need to supplement such quantitative analyses with qualitative (verbal) analyses, so that vital, but currentiy unquantifiable, information may be taken into account. It is in this spirit that this report is offered.

The report consists of a presentation and distillation of major nontechnical issues surrounding commercial waste management, followed by ethical, institutional, and political analyses of these issues. The ethical analysis consists of a discussion of what is meant by "ethics" and "morality" in the waste management context and an illustrative attempt at an ethical analysis of the commercial nuclear waste problem. Two institutional analyses are presented: one is an analysis of the 
possible problems of long-term human institutions in waste management; the other is a presentation of institutional arrangements for the short term. A final chapter discusses issues and concerns involving intergovernmental relations--that is, local, state, and federal interface problems in waste mangement.

Because the intent of this volume is to cite a wide variety of viewpoints, and because these viewpoints are not critically evaluated, the reader should be cautioned that the authors do not intend to imply that all such viewpoints have equal merit. The reader, who will undoubtedly regard some points of view as being more correct than others, may see the treatment as "biased" in the sense of giving space to a viewpoint which is (in his mind) incorrect. What is needed, of course, are critical evaluations of each major perspective. It is hoped that such work will be done in the near future.

Nonetheless, evaluation-free discussions of these issues are not completely feasible. The individual authors take full responsibility for these statements. John Hébert coordinated the work for this volume and wrote this introduction. William Rankin wrote Chapter II. Peter Brown, of the University of Maryland, and William Rankin wrote Chapter III. Chapter IV was written by C. R. Schuller, and Chapter V by Randall Smith. Finally, C. R. Schuller, Henry Lippek, and Jill Goodnight contributed to Chapter VI.

This work was sponsored by the U.S. Department of Energy, formerly the Energy Research and Development Administration. However, a 11 opinions should be attributed to the authors and do not in any way represent the position of the sponsor.

Finally, we are indebted to the following persons who made extensive comments on this manuscript: Daniel Callahan, Gerald Garvey, Harolá Green, Roger Kasperson, Ida Hoos, Laurence Moss, and Eugene Skolnikoff. In addition, we thank our Battelle colleagues, Carl Unruh, Max Kreiter, and John Bartlett for their valued comments.

Of course, all statements, errors, and omissions are the sole responsibility of the authors. 


\section{CHAPTER I I}

\section{ISSUES RELEVANT TO COMMERCIAL}

\section{NUCLEAR WASTE MANAGEMENT}

The public issues relevant to commercial nuclear waste management are numerous, interrelated, and highly complex. They involve technical, legal, political, economic, moral, and/or psychological considerations. Because of this complexity and because of large differences in human value systems, people's perceptions of and opinions on these issues vary greatly.

This document discusses the waste management issues that have been considered in public forums, articles, brochures, and the media. It also attempts to indicate the range of perceptions on these issues. An issue is an unsolved problem or potential problem that has been perceived by persons or groups to require broadly based consideration. Radioactive waste management has been perceived by some to be a purely technical problem. To others, it has been perceived as a technical problem imbedded in social, ethical, and institutional issues. Moreover, the lack of demonstration of practical technology has permitted escalation of the latter viewpoint.

As prelude to the description of the issues, a brief discussion of human values is given. This should provide a perspective as to why human perceptions of waste management issues differ so widely and why these differences are difficult, if not impossible, to reconcile.

\section{HUMAN VALUES PERSPECTIVE}

The human values perspective of Rokeach $(1,2)$ provides a useful framework for understanding why there are such large differences among individual perceptions of unsolved waste management problems. Rokeach believes that the most important determinants of human perceptions and behavior are human values.

Human values are conceived to be beliefs that certain modes of conduct (such as being honest, loving, or competent) and certain 
end-states of existence (such as salvation, a world of beauty, and family security) are personally or socially preferable to their opposite modes of conduct or end-states of existence. Values concerning modes of conduct are called instrumental values; values concerning end-states of existence are called terminal values. Although little human value research has been done in the waste management area to date, certain values that Rokeach discusses are relevant to nuclear waste management, as well as to other energy generation issues. These include, for example, a comfortable life, pleasure, family security, national security, a world of beauty, freedom, equality, and a world at peace.

Rokeach feels that every person possesses a relatively small number of values; he has identified 18 terminal and 18 instrumental values. Each value differs in the amount of importance that a person ascribes to it as a guiding principle in life. For example, one person might believe that a world of beauty is a more important terminal value than a comfortable life; another may place more importance on a comfortable life than on a world of beauty. The first person is more likely to perceive nuclear wastes as posing environmental risks, and the second is more likely to perceive these risks as small enough to allow the generation of more nuclear waste.

It is important to note in this example that both of these people see a world at peace and a comfortable 1 ife as important guiding principles. The difference in their behaviors is determined by the perceived relative importance of these two values. The set of relationships determined by the relative importance among al1 18 of a person's terminal values comprises a person's terminal value system. Likewise, the set of relationships determined by the relative importance among all 18 of a person's instrumental values comprises a person's instrumental value system.

Terminal and instrumental value systems differ greatly from person to person because of the differing social, psychological, and physical environments in which persons are raised. After people reach a certain stage in life (probably late adolescence), their value systems remain rather stable: it becomes harder and harder to change the relative importance of the individual values within the value system. 
Human values are seen by Rokeach as occuping a central role in determining behavior for several reasons: they serve as standards for guiding and explaining conduct; they serve as a basis for conflict resolution and decision making; and they serve to motivate behavior. Also, human values influence other types of human cognitions such as perceptions, opinions, and attitudes.

Given the large individual differences in human value systems, the stability of the value systems, and the important functions that human values serve, it becomes more apparent why there is such a large range of perceptions on waste management issues and why these issues are difficult to resolve. Little research has been done to determine how human values, as conceived by Rokeach, are related to the different perceptions of waste management issues. Thus, in the discussion of the issues that follows, these value-perception relationships are presumed to exist but are not defined.

\section{WASTE MANAGEMENT ISSUES}

This section provides definition and description of public issues associated with radioactive waste management. It includes the issues that have arisen out of the nuclear debate literature and other issues that have been identified by individuals involved with waste management. It gives special attention to the Conference on Public Policy Issues in Nuclear Waste Management, 1976, (3) hereafter referred to as the Public Policy Conference.

The issues reflect consideration of three major fuel cycle modes: the once-through cycle, uranium-only recycle, and uranium and plutonium recycle. The type of fuel cycle mode used can have an effect on some of the issues presented below; this fact is noted, where appropriate, in the text. It is also important to note that recent (1977) Presidential policy impacts on the recycle issue. This policy states that the United States will defer indefinitely reprocessing and recycling of plutonium produced in the nuclear power program and will redirect the funding of nuclear research and development programs into alternative nuclear fuel cycles that do not involve direct access to materials usable in nuclear weapons. Although this policy could quickly change, it does rule out 
plutonium recycle at this time: it does not rule out reprocessing of spent fuel in which weapons material is not isolated.

Finally, it is important to note that there are those who find it difficult to distinguish between nuclear waste management issues, per se, and the more general question of whether to proceed with nuclear power. This difficulty surfaced frequently at an (1977) Environmental Protection Agency Workshop in Albuquerque, New Mexico, and at the Public Policy Conference (1976). In a paper presented at the conference, (4) Abrahamson postulated that the more general question of whether to proceed with nuclear power may well be answered by our ability to handle the waste management issues. However, even if the United States does not continue to use nuclear power, radioactive wastes exist at this time, and there is full agreement on all sides that something must be done about these wastes.

Issue 1: Dislocation of Risks and/or Benefits to Future Generations.

One major waste management issue concerns the present generation's moral obligations to future generations regarding the transfer of risks and/or benefits (see Chapter III for a more thorough discussion of this issue). This issue is complicated by the fact that it is very difficult to specify with any certainty what the transfer costs and benefits will be. One perception of this issue follows $\left(\mathrm{see}^{5,6,7}\right)$. At present it is not commercially and technically feasible to transform the highly radioactive waste products into more short-lived forms. Therefore, because of some of the long-1ived actinides, most notably plutonium 239, the wastes may have to be isolated from the biosphere for several hundred thousands of years. Monitoring and surveillance of the wastes by future generations will be necessary because human beings do not have sufficient long-term experience with the kind of containment that is required to provide adequate assurance that the integrity of the containment will be preserved. Breach of containment could result from either human action or natural causes, and the costs and risks associated with corrective action cannot be adequately assessed. Those holding this perception believe that these wastes could put future generations at potentially great risk for the benefits that present generations receive, and that these benefits may be small or unnecessary, considering our present standard of living. Given these unknown 
risks and benefits, they feel that it would be morally irresponsible for present generations to produce more nuclear wastes.

There are others, however, who do not perceive the risks from radioactive wastes to be great. Comar, ${ }^{(8)}$ for instance, does not perceive radioactive materials to be unique in terms of long-term effects. For instance, lead and mercury never change atomic structure, and, therefore, can remain dangerous literally forever. The perception still remains, however, (see ${ }^{5}$ ) that radioactive material is unique because some of it, especially the actinides, is largely manmade.

Rodger's (9) perception of the issue is that radioactive wastes are not dangerous to society as a whole for more than 500-700 years. It is a fact that after about 700 years $(10,11)$ most of the fission-product radioactivity will have decayed away. The remaining radioactivity is due to the long-lived materials such as plutonium 239, iodine-129, and technetium-99. Rodger ${ }^{(9)}$ feels that after 500-700 years the risk would no longer involve a large number of people. The remaining potential risk would be to the relatively few persons who might disrupt isolation. If this perception is correct, then monitoring and surveillance of the site may be unnecessary, or needed for only a relatively brief period of time. This issue is more fully discussed in Chapter IV.

Some individuals, Bodansky and Schmidt, for example, $(12,13)$ perceive that a waste management system that will insure containment integrity for a period of time sufficient to put future generations at virtually no risk is possible now. They perceive that even if manmade containment is breached, geologic factors will keep biosphere contamination from occurring.

A third general perception can be attributed to some who view the waste management debate more globally. This perception (see $10,14,15,16$ ) is that when we assess our obligations to present and future generations, other risks and benefits besides those of radioactive wastes must be considered. For instance, the burning of hydrocarbons to produce electricity is helping to deplete an important nonrenewable resource and is causing a build-up of carbon dioxide concentration in the atmosphere that may have profound effects on worldwide climatic conditions. How do the future risks associated with emphasis on fossil fuels compare with 
those for nuclear wastes? This viewpoint asserts that all of the risks and all of the benefits of all sources of energy should be carefully considered so that an overall energy policy can be designed; examination of the costs and risks of radioactive wastes to future generations is but part of the discussion that should take place.

The fuel cycle mode affects this issue. Although there will be some long-lived actinides in the waste regardless of the fuel cycle mode, if plutonium were recycled and burned as a reactor fuel, potential risk with regard to plutonium waste disposal, at least, would be less.

What values affect the perceptions of this issue? A study by Maynard, Nealey, Hébert, and Lindel1 (17) found that with regaret to nuclear waste management factors: nuclear technicians placed more importance on short-term safety than long-term safety; environmentalists placed more importance on long-term safety than short-term safety; other groups (public utility employees, students, and church and civic organization members) placed equal importance on short-term and long-term safety. The Rokeach ${ }^{(2)}$ value concept analysis suggests that these perceptual differences arise because of basic differences in the perceived relative importance of family security and future security. Also, differences in the perceived importance of instrumental values that deal with morality and competence are probably implicated, as well. For example, those who consider instrumental moral values--such as being responsible and loving--to be very important might be the most concerned about future generations. On the other hand, those who place more importance on instrumental competence values--such as being logical, competent, and intellectual--might be more technically oriented and thus more likely to believe that the technical community has solved or can solve the waste containment problems.

\section{Issue 2: Need for Candor.}

The need for candor to the public from those involved in nuclear waste management was an issue discussed at the Public Policy Conference $^{(3)}$ and on a National Broadcasting Company television program entitled "Danger! Radioactive Waste" (January 26, 1977). The issue basically hinges on how the public perceives information that is provided by the federal government and the nuclear industry on nuclear 
wastes. Reporting of incidents involving migration of radioactivity at Maxey Flats and leaking of radioactive wastes from tanks at Hanford have led segments of the public to perceive that they aren't being provided with all of the relevant information as soon as possible. This perceived lack of candor is not a new issue, however. Palfrey, ${ }^{(19)}$ for example, discussed how the problem of AEC secrecy had a strong effect on public confidence in the AEC as early as 1953.

Differences in perceptions about government and industry candor also lead to differences in perceptions as to what information is important for release to the public. For instance, a leak of radioactivity-contaminated cooling water into the Columbia River at the Hanford Reservation was not reported to the press for several days because company spokespersons perceived the amount of radioactivity to be insignificant. A Seattle Post-Intelligencer editorial a week later (November 30, 1976), however, provided evidence for an opposite perception. The editorial stated that more candor was needed about Hanford leaks and that private firms did not have the right to determine what the public should hear about such events regardless of the amount of radioactivity released.

Finally, there are different perceptions about the amount and quality of information concerning wastes that has been made public. Since 1954, more technical articles and policy statements have been written, and more rhetoric spoken about nuclear power than most other technical-social issues of our time. Some perceive this to mean that the nuclear establishment is being candid. Others perceive this in a very different way. Green, ${ }^{(20)}$ for instance, believes that there has been a calculated policy on the part of the nuclear establishment since 1954 to deluge the public with a flood of highly technical information that could not possibly be understood. He feels that this has been done in order to support and perpetuate the myth that the public has to rely on the judgment of scientific and engineering experts for wisdom on what should be done with nuclear waste. In other words, he questions whether information that can be understood by the public is being provided by the nuclear establishment.

The candor issue is related to many of the other issues. The focus seems to be on how much confidence the public has in the federal government and the nuclear industry. If there is little or no confidence in 
these institutions, then there will always be disagreement on any of the problems associated with nuclear waste.

Issue 3: Public Involvement.

The public involvement issue deals with how and to what extent the public should be involved in public policy decisions regarding nuclear waste management. The what and how of public involvement were major topics of discussion at the Public Policy Conference. (3) The perceptions presented at this conference are summarized below.

There was general agreement by panelists at the conference on the perception expressed by Green ${ }^{(20)}$ that any person, group, or institution that wants to be involved in nuclear waste policy decisions has that right. Green also felt that the decision-making process should be so structured as to give every member of the public sufficient information in order to permit him or her to become interested and, it is hoped, involved. The decision-making process should also be open and fair, not only appear to be fair, ${ }^{(21)}$ and the process should provide the maximum opportunity for feedback, in both directions, between the government and the public. (20) All of these points are intimately related to the candor issue.

Skolnikoff(21) also pointed out that public participation does not guarantee either sensible decisions or an understanding of the issues. However, public participation is necessary to respond to the public's increasing wariness of new technologies and to help reach acceptable decisions.

Skolnikoff(21) also discussed some actions that he perceives could help to make the decision-making process open and fair. These include (a) opening up the policy discussions to the public from the early stages, (b) involving institutions other than those directly implicated in the process, (c) having outside reviews done of major policy analyses, and (d) holding public forums.

There is general agreement that the federal government (especially the President, Congress, and agencies such as DOE) has final responsibility in the decision-making process. There are individuals, e.g., Ignatius and Claybrook, ${ }^{(6)}$ however, who perceive that the public should 
have very strong input on waste management issues, through, for example, state initiative efforts.

It is not easy to postulate which human values bear on this issue. Public involvement might not be such an important issue if the public had more confidence in the federal and nuclear industry decision makers. Thus, it is likely that some people feel that the values they prize highly are not being addressed with sufficient importance. Consequently, they may desire to become involved in the decision-making process, not because of a lack of trust or confidence, but because they feel strongly enough about some of their values related to waste issues that they wish to protect those values in an active, direct manner. Thus, value for a comfortable life, a world of beauty, family security, national security, being logical, and being responsible may be important determinants for some people's desire to enter the decision-making process.

Issue 4: Uncertainty.

There are many types of uncertainty involved with radioactive waste management. Some are associated with previously discussed issues, e.g., uncertainty about whether the wastes can be disposed of adequately to protect present and future generations, and uncertainty about whose statement can be trusted regarding waste disposal.

There are also three other types of uncertainty discussed in this section: (a) uncertainty regarding the effects of low levels of radiation received in low doses over long periods of time; (b) uncertainty about whether the wastes can be kept out of the biosphere for long enough periods: (c) uncertainty regarding human fallibility and malevoTence.

There appears to be no practical, direct way to determine the genetic and health effects of low levels of radiation received in low doses over long periods of time in an experimental setting. At low radiation rates and doses, radiation effects on cancer incidence, for example, are not great enough to measure. The guidelines for radiation doses of the U.S. Environmental Protection Agency have therefore been set by using findings from research on animals and by examining people who have received high dose rates over short periods. The guidelines 
are extrapolated in a linear fashion from incidences of cancer induced from high dose rates received over short periods of time to predict the incidence of cancer from low dose rates received over long periods of time. The basic issue, then, regards the validity of the assumption (called the "linear hypothesis") that incidence of cancer from low dose rates can be linearly extrapolated from known incidences of cancer from high dose rates.

Because of the uncertainty involved with the linear hypothesis, some, Gofman for example, (22) perceive that low dose rates over long periods can have serious effects and argue that the guidelines should be more stringent. Others, for example, Cohen, (10) perceive the risks to be very sma11--much smaller, for instance, than the risks associated with smoking or driving. In general, however, there is agreement that the guidelines as estimates of the effects of low levels of radiation at low dose rates are conservative. (23)

Uncertainty about whether wastes can be kept out of the biosphere until they are harmless was an important issue at the Public Policy Conference. (3) There are several aspects to this issue, but uncertainty regarding the geologic stability of the waste repository is usually the main focus of discussion. The waste technologists have viewed salt deposits, for instance, as likely repository sites because some salt deposits have been stable for millions of years and the presence of salt means that there is no water present to return the radioactivity to ground water.

However, there is no way to assure with total certainty that the geologic structure won't change and that radioactivity won't be released. Thus, there were some at the Public Policy Conference who perceived this to be a serious issue. 'The Flowers Report (24) perceived that the main uncertainty here was due to climatic changes and alterations in sea level rather than to changes in geologic structure.

The last uncertainty issue to be discussed involves human fallibility and malevolence. Humans are fallible and sometimes malevolent; what is uncertain is how to include these factors when determining the probability of a waste-related accident or release. Hardin ${ }^{(25)}$ perceives the probabilities that have been calculated for such incidents as 
inaccurate and much too low. Others, Schmidt and Bodansky, (13) for example, perceive that the probabilities are accurate enough to use for policy-making purposes.

There are enough issues involving uncertainty to have caused uncertainty itself to become an issue. Some people perceive the uncertainty and say "Stop producing wastes" or "Let's proceed slower and with more caution." Others perceive the same uncertainty and believe that we should proceed. How people respond to uncertainty, especially when it involves health and safety risks, may be closely related to human values involving health and security considerations as well as values such as an exciting life.

Issue 5: Risk and Equity Issues.

As implied earlier, many of the uncertainty issues involve genetic and health risks. For instance, uncertainty about geologic stability means uncertainty about genetic and health risks to future generations. However, increased uncertainty does not always imply increased risk, and it is important to maintain this distinction. For instance, it gets harder to predict geologic stability as we try to predict further into the future. Potential risk however, decreases with time because of radioactive decay.

There are two other risk issues that will be discussed here. The first relates to how risks are perceived. The second relates to the distribution of risk related to radioactive wastes and some accompanying equity considerations.

What is risk? The risk of an event is defined, in a technical sense, as the probability that the event will occur multiplied by the expected outcome of the event. For example, suppose that a radioactive release could occur with probability .002 per year, and, if it did occur, 10,000 people could die. Then, risk is $.002 \times 10,000=20$ deaths expected per year on the average from this type of accident.

The technical community concerned with risk estimation calculates risks numerically and compares them quantitatively. To date, risk estimates that have been made for waste management indicate that the calculated risks are low in comparison with risks commonly experienced 
(e.g., auto travel, death by lightning). Moreover, the technical community tends to accept risk estimates at face value.

In contrast, the general public often perceives the outcomes of an event to be more important than the probability. $(26,27)$ This may be due to the fact that the public is familiar with Murphy's Law: If something can go wrong, it will go wrong. Thus, probabilities are often perceived to be less meaningful than outcomes.

However, it is not only the general public that considers outcomes to be more important than probabilities in certain situations. This often occurs in the world of business and industry, and a good example is provided by the nuclear area. Insurance companies would not insure nuclear reactors for unlimited liability because they lacked a data base for actuarial calculations and because one large accident, regardless of how improbable the accident was, could ruin the insurance companies. After an upper liability limit for a nuclear reactor accident was set by the Price-Anderson Act, the nuclear industry was able to obtain the amount of insurance needed to cover the upper liability limit and could then proceed with nuclear power. A North Carolina district court decision (March 31, 1977) declared the Price-Anderson Act an unconstitutional deprivation of property without due process of law. This ruling, however, is being challenged in higher courts, so that its final effect on the establishment of upper liability limits is not yet clear.

Value differences in the technical and the nontechnical communities influence their perceptions of risk. The technical community places great importance on being intellectual and logical; this leads them to perceive risk estimates relatively objectively. The nontechnical public, especially those persons who place great importance on health and security values, would tend to focus more on the outcomes of an accident.

Another important risk issue related to radioactive waste disposal is the distribution of risk due to the geographic location of a waste repository. Should a person who possibly does not benefit from nuclear power be put at risk because of the proximity of a waste repository? Should residents of a state having a waste depository be put at risk from radioactive wastes generated in other states?

Some people perceive the equity problems due to the concentration of risk at a waste repository to be very important issues that have not 
been addressed adequately in the decision-making process. For example, there is no mechanism in place for compensating a person who lives near a waste repository for being involuntarily placed at risk and none for compensating the person if he or she actually suffers genetic or health damage either now or in the future. Some people also feel that the risk is placed in greater proportion on some groups such as the poor and minorities.

It has been pointed out that the technical optimists perceive that the compensation is almost automatic. For example, the average life expectancy is far longer now than it was 100 or 200 years ago because of advances in the fields of medicine and nutrition. Also, the present generation is the recipient of technical knowledge and capital investments passed on by previous generations. Whether one perceives this compensation to be adequate or whether one feels that compensation should be more event-specific will determine how one perceives the importance of the equity considerations. This issue is discussed more fully in Chapter III.

\section{Issue 6: Safeguards and Civil Liberties.}

The safeguards and civil liberties issue hinges largely upon the fact that plutonium, a natural outcome of the nuclear fission process, is the major material used in nuclear weaponry. Reprocessing technology therefore bears strongly on this issue. If plutonium is never separated from the spent fuel, then terrorist opportunities to build a plutonium bomb are affected, since plutonium obtained for weapons fabrication in spent fuel form would have to be reprocessed.

If weapons-grade material is reprocessed, then there are two basic safeguards considerations: materials accountability and security. There are various perceptions of the ability to adequately safeguard nuclear weapons material. Willrich and Taylor ${ }^{(28)}$ perceive the accounting safeguards as inadequate. A larger worry of some relates to their perception of the police force and of police tactics that might be necessary either to prevent nuclear thefts or to recover nuclear material, once it has been stolen. This perception was expressed in the Flowers Report ${ }^{(24)}$ which stated that the security force might need to play 
. . an active role. . . that is, to infiltrate potentialiy dangerous organizations, monitor the activities of nuclear employees and members of the public and, generaliy, carry out clandestine operations. Such operations might need to be conducted on a scale greatly exceeding what would otherwise be required on grounds of national security in democratic countries. The fear is expressed that adequate security against nuclear threats will be obtained only at the price of gradual but inexorable infringements of personal freedom. $(24, p .32)$

There are other perceptions on the safeguards issue. Cohen ${ }^{(29)}$ perceives that plutonium is an overrated weapon for terrorist purposes. The theft of radioactive materials and the construction of a bomb is a risky undertaking: he has estimated that a terrorist has a $50 \%$ chance of being killed during a theft and a $30 \%$ chance of dying while attempting to build a bomb. Cohen also presents the argument that there are other more efficient means for terrorists to use, e.g., poisoning a city water supply or releasing poisonous gas.

There are also differences in perception on what constitutes an adequate security force. Schmidt and Bodansky, (13) for instance, do not believe that safeguards must necessarily involve clandestine operations. They believe that a guard force could adequately safequard radioactive materials much as the U.S. Army has done successfully for the past 30 years. What is perceived to be important here is that the guard force be carefully screened, selected, and adequately trained, and that it be of sufficient size.

There is also a large difference in the perception of how easy it is to build a nuclear bomb. Some, Ignatius and Claybrook, ${ }^{(6)}$ for example, believe that almost anybody with access to the public library can build an atomic bomb. The view of Schmidt and Bodansky (13) is that this task would require, at the least, a small team of wel1-trained technical personnel with special talents and access to good laboratory facilities.

The differences in perceptions on this issue might be closely tied to human values related to security, since some are worried about safety from terrorism. However, it is likely that valuing of freedom plays a large role here. Those concerned about freedom would be most concerned about possible losses of civil liberties. 
Issue 7: Conservation and Alternative Power Production.

How one perceives the ability of conservation and alternative power production (other than nuclear) to meet power needs will affect perceptions of nuclear waste issues. If one perceives that conservation will take care of increased energy needs or that other power sources are superior (cheaper, less polluting, etc.), then one would be less inclined to believe that the United States should continue to produce nuclear wastes.

This is basically the position taken, for example, by Millerd ${ }^{(30)}$ who believes that the United States should not produce more nuclear wastes in the production of electricity until the United States has tried energy conservation and exhausted other means of alternative power production. A slightly different point of view was developed in a case by the Sierra Club filed against the Potomac Electric Power Company regarding the Douglas Point nuclear plant. The Sierra Club perceives that the mechanisms now in place for making decisions either to use more energy or to conserve energy are biased very strongly toward energy supply and against energy conservation. The club argued that until proper pricing of electricity is achieved, and the effect this has on energy supply and demand is observed, the true effects of conservation and comparative costs of alternative energy cannot be determined.

Most agree that conservation is necessary. However, many perceive that few people seem to be participating voluntarily in conservation, especially as the United States forgets the 1973 Arab oil embargo. (31) There are some other related perceptions on this issue. One is that even with conservation, increased energy production is still necessary because of anticipated population and economic growth. Another perception is that regardless of energy supply and demand issues, the United States should replace the electrical energy now supplied by gas and oil with some other power source, possibly nuclear. Finally, some individuals $(32,13)$ perceive that alternative power sources have disadvantages that make nuclear power more attractive. For example, coal is seen as more detrimental to the environment than nuclear power, solar energy is not yet economically suited for electrical power production (although end-use substitution is possible with solar space and water heating), 
and other alternatives such as fusion are not technically feasible at this time and may or may not be proven possible.

It seems reasonable to hypothesize that the importance placed on a world of beauty has influenced individual perceptions of this issue. This is because environmental groups, whose existence centers around preserving a world of beauty, have been among the first in urging conservation and alternative power production rather than increasing the use of energy. Most individuals believe that a world of beauty has some importance as a guiding principle in their lives. However, relatively speaking, environmental groups place more importance on this value, which leads to differences in perceptions about energy supply and demand.

\section{Issue 8: Transportation.}

As the nuclear program grows to the projected size of about 350 reactors by 2000 A.D., the amount of waste, and, therefore, the number of waste transport shipments will similarly increase. This fact relates to some of the issues discussed earlier. One perception is that a large number of shipments will greatly increase the chances for terrorism and sabotage. This is related to the safeguards and civil liberties issues and to health and safety factors. Increasing the number of waste shipments will increase the number of transportation accidents. Some, therefore, perceive potential high risks to health being involuntarily placed on some of the people involved in such transportation accidents.

Under current regulations, high-level radioactive wastes must be shipped in nonliquid form in specially constructed steel canisters designed to withstand a severe accident. Container design and shipping procedures are regulated by the Nuclear Regulatory Commission and the Department of Transportation. Whether these precautions are adequate is, of course, debated by some, but the technical community perceives them as such. Other discussions of this issue can be found in chapter IV.

Issue 9: Institutional Issues.

The institutional issues involved with waste management have not been discussed as extensively in the nuclear debate literature as have other issues. This is probably due to several factors: (a) most people 
are not familiar with how institutions function and interact; (b) institutional issues don't involve as directly, at least, health and safety considerations; and (c) institutional issues more closely relate to how the job of waste management wi11 be performed rather than whether wastes should be produced in the first place.

There are two issues that will be discussed here. The first is individual perceptions on whether institutions can be designed in the short term to handle nuclear wastes. The second involves long-term institutional issues with regard to long-term waste management. Other more specific problems are discussed in Chapters IV and V.

The first issue is concerned with perceptions about the kind of institution necessary to manage the disposal of nuclear wastes. Some individuals look at past accidents and leaks of military wastes and perceive that present institutional arrangements are not adequate. Conversely, others perceive that present institutions are doing an adequate job. Willrich(33) feels that a public corporation should be designed to handle the wastes. This public corporation would pay for the costs of disposal by charging the reactor operators for the expenses. The issue of responsibility for ownership and operation of waste disposal facilities is unresolved.

The most general issue regarding long-term institutions for monitoring disposed wastes is whether these institutions are necessary and for how long. Certainly, some in the technical community (13) feel that the technical considerations will have made monitoring almost unnecessary. They believe that if nothing happens to the wastes within the first 10 to 30 years after disposal, then nothing is ever likely to happen. Others ${ }^{(6)}$ perceive that institutional arrangements for monitoring cannot be made because the wastes may have to be monitored for as long as 200,000 years due to the presence of plutonium. Finally, there is an intermediate perception (see the discussion of Institutions in Long-Term Nuclear Waste Management, Chapter IV). This viewpoint is that monitoring might be needed during the first 100 to 700 years; after that, information at the site could prevent subsequent intrusion of the waste repository. 
Issue 10: Irreversible Decisions.

This issue is concerned with the timing of irreversible decisions about waste disposal. Some people perceive that we should dispose of wastes in an irreversible manner because that will provide the safest disposal system for present and future generations. Others would defer irreversible disposal decisions for several reasons. One perception of the issue is that, because of uncertainties about geologic stability, we should wait for some period of time, say 20 to 50 years, before making the waste irretrievable. Then, if a certain type of waste disposal system fails, the wastes can be removed and disposed of elsewhere or in a different manner. A 30 to 50 year deferment on the decision to irretrievably dispose of the wastes would also leave open the option to use a better waste management system if one is devised during this period.

Given that some of the radioactive wastes either have practical value now or may have in the future, some people feel that we should not make irreversible decisions regarding wastes until we know whether they are needed. ${ }^{(34)}$ This argument is especially pertinent if the oncethrough fuel cycle is used, because the used, unrecycled fuel rods still contain uranium and plutonium. Retrievable management of such fuel would preserve the options of future generations.

Rochlin ${ }^{(34)}$ has suggested that site multiplicity and technical irreversibility (resistance to release by accident or recovery by technology) should be the major social criteria for determining a waste management plan. He argues that the more sites used and the more irreversible the waste management process, the smaller the danger to present and future generations. However, this would greatly limit the options of future generations. Conversely, a single site with a highly reversible technology would not limit future options, but could present more health and safety hazards.

Methods or techniques for determining what the trade-offs should be between health considerations and maintaining options have not yet been developed. The issue of how these trade-offs are related specifically to a waste management system incorporating site multiplicity and technical irreversibility is still unresolved. 
Issue 11: Commercial versus Defense Wastes.

This issue concerns an apparent distinction between commercial and military wastes. In discussions at the Public Policy Conference, Abrahamson ${ }^{(4)}$ acknowledged that the commercial and military wastes differed from a regulatory standpoint, but felt that the constraints on the management of one should be the same as on the other. His perception of this issue was that the distinction is being made in order to dissociate commercial and defense waste management. However, Hardin (35) has argued that the distinction should be kept because of differences in waste form and waste inventory.

Others perceive that distinctions should be kept between existing wastes and future commercial wastes. For example, high-level defense wastes generated at Hanford and commercial wastes generated at the West Valley, New York, reprocessing plant were neutralized, i.e., caustic was added to the waste solution, which is initially acid. If commercial fuel is reprocessed in the future, the high-level waste solution is not expected to be neutralized.

Issue 12: International Responsibilities Regarding Waste Management and Reprocessing.

The issues surrounding international responsibility regarding commercial waste management were raised by Ignatius and Claybrook in $1974^{(6)}$ and later at the Public Policy Conference. (3) The issues involve, inter alia, the responsibility of the United States regarding reactors sold abroad, the problem of changing national boundaries, whether each nation that has or wishes to have nuclear power generating facilities also has sufficient geologies for disposal, and problems regarding seabed disposal. In addressing these issues, the United States must consider genetic and health risk factors, possibilities for weapons proliferation, and responsibilities to less-developed countries regarding economic development.

Three perceptions are relevant here. Ignatius and claybrook (6) have expressed the worry that United States citizens may develop genetic and health problems due to worldwide releases of rádioactivity. Willrich $^{(33)}$ has suggested that an International Waste Authority be established under the International Atomic Energy Agency to handle this 
problem. Second, the perception was voiced at the Public Policy Conference ${ }^{(3)}$ that the less-developed nations might not exercise good waste management practice. In these countries, cost could more easily influence waste management strategy than in the more wealthy countries. Third, the United States should be aware of the fact that our waste management policy can influence the waste management policy of other nations. No one nation has yet demonstrated a solution to all operations of radioactive waste management.

Issue 13: Costs of Waste Management.

In some ways, the cost of a waste management system is not an issue. There seemed to be widespread agreement at the Public Policy Conference $^{(3)}$ that we must be willing and able to pay for an adequate waste disposal system. Rochl in ${ }^{(34)}$ suggested that the cost factor for different waste management strategies should be considered last, after all of the other criteria have been considered. A study by Maynard, Nealey, Hébert, and Linde11 ${ }^{(17)}$ indicated that public values regarding short-term risks, long-term risks, and accident detection and recovery are perceived to be more important by the public than cost in a waste management strategy. Certainly, some types of waste management strategies may be too costly to implement at this time, such as disposal into outer space. Kubo and Rose, (11) however, projected that most waste management strategies would usually cost less than $1 \%$ of the total cost of the electricity generated--a price that most seem willing to pay.

Payment for disposal of commercial radioactive wastes has been defined by 10 CFR 50, Appendix F. The nuclear industry would be responsible for paying the government a fee at the time of transferring its waste to federal custody. This fee, together with interest on unexpended balances (presuming a TVA-type of trust fund) is supposed to pay the costs of constructing and operating a repository, plus "perpetual care." The regulation, however, does not define a cut-off point between development of disposal techniques, which the government pays for, and construction, which would be charged through the fee to the nuclear industry, nor has this cut-off been defined by the Office of Management and Budget or Congress. At this time, the size of the fee has arso not been determined. 
Numerous interrelated and complex issues involving technical, lega1, political, economic, moral and/or psychological concerns are relevant to the management of commercial nuclear waste. Two of the issues--the need for candor and for public involvement in the decisionmaking process--are perceived at this time as very important by segments of the public, and seemingly transcend the other issues, which are more specifically related to nuclear waste management. The most significant of the other issues is concern over the dislocation of risks and benefits to future generations that are a result of present day waste production and waste management practices. Other important public issues that were discussed include: uncertainty regarding the effects of low levels of radiation received in low doses over long periods of time; uncertainty about whether nuclear wastes can be kept out of the biosphere for long enough periods of time; uncertainty regarding human fallibility and malevolence; risk perception; the distribution of risk with regard to waste management and accompanying equity concerns; safeguards and civil liberties; conservation and alternative power production; transportation; institutional issues regarding the ability of institutions to manage nuclear wastes now and over long time periods; the timing of irreversible decisions; the distinction between commercial and military wastes; international responsibilities regarding waste management and reprocessing; and, cost of waste management.

The human values theory of Rokeach $(1,2)$ was also presented to provide perspective as to why individual perceptions of these issues vary so greatly. The relationships between specific values and specific waste management issues were discussed when possible. Given the importance of human values as life-guiding principles, and given the differences between people on the relative importance that they place on their values, it follows that nuclear waste management issues can never be fully resolved to everybody's satisfaction. However, understanding the basis for and range of perceptions on these issues may help to lay the groundwork for waste management decisions that are responsive to public concerns. 
1. M. Rokeach, Beliefs, Attitudes, and Values. Jossey-Bass, San Francisco, CA, 1968.

2. M. Rokeach, The Nature of Human Values. The Free Press, New York, NY, 1973.

3. Conference on Public Policy Issues in Nuclear Waste Management, Chicago, IL, October 27-29, 1976.

4. D. E. Abrahamson, "Social, Ethical, and Moral Issues in the Implementation of Radioactive Waste Management Objectives." Paper presented at the Conference on Public Policy Issues in Nuclear Waste Management, 1976 (see n. 3).

5. National Council of Churches. "The Plutonium Economy: Study Material for the Proposed Policy Statement." National Council of the Churches of Christ in the U.S., 1975.

6. N. Ignatius and J. Claybrook, eds., A Nuclear Catastrophe is Too Big a Price for our Electric Bi11: A Citizen's Manual on Nuclear Energy 1974. Center for the Study of Responsive Law, Washington, DC , 1974.

7. P. P. Micklin, "Environmental Hazards of Nuclear Wastes." Science and Public Affairs, pp. 36-42, April 1974.

8. C. L. Comar, "Plutonium: Facts and Inferences." EPRI Journal, pp. 20-24, November 1976.

9. W. Rodger, Comments made at the Conference on Public Policy Issues in Nuclear Waste Management, 1976 (see n. 3).

10. B. Cohen, "Perspectives on the Nuclear Debate." Bulletin of the Atomic Scientists, pp. 35-39, October 1974.

11. A. Kubo and D. Rose, "Disposal of Nuclear Wastes." Science 182: 1205-1211, 1973.

12. D. Bodansky and F. H. Schmidt, "Safety Aspects of Nuclear Energy," The Nuclear Power Controversy. A. W. Murphy, ed., Prentice-Ha11, Inc., Englewood Cliffs, NJ, 1976.

13. F. H. Schmidt and D. Bodansky, The Fight over Nuclear Power.

Albion Publishing Co., San Francisco, CA, 1976.

14. D. Rose, Comments made at the Conference on Public Policy Issues in Nuclear Waste Management, 1976 (see n. 3).

15. M. Maxey, "Exorcising Nuclear Demonry: Ethics versus Ideological Politics." Paper presented at the Atomic Industrial Forum workshop entitled Nuclear Information Strategies: New Settings, New Approaches, The Sands, Las Vegas, NV, September 26-29, 1976. 
16. World Council of Churches, "Report on Nuclear Energy." Anticipation $21,1975$.

17. W. S. Maynard, S. M. Nealey, J. A. Hébert, and M. K. Lindell, Public Values Associated with Nuclear Waste Disposal. BNWL-1997, Battelle, Pacific Northwest Laboratories, Richland, WA, 1976.

18. National Broadcasting Company, "Danger! Radioactive Waste." NBC Reports, January 26, 1977.

19. J. G. Palfrey, "The Problem of Secrecy." The Annals of the American Academy of Political and Social Science 290:90-117, 1953.

20. H. P. Green, Comments made at the Conference on Public Policy Issues in Nuclear Waste Management, 1976 (see n. 3).

21. E. B. Skolnikoff, "Implementation: Action or Stalemate?" Paper presented at the Conference on Public Policy Issues in Nuclear Waste Management, 1976 (see n. 3).

22. J. W. Gofman, "The Cancer Hazard from Inhaled Plutonium." Committee for Nuclear Responsibility, Yachats, OR, 1975.

23. B. Wolfe, "Letters." Science 194:478-479, 1976.

24. Sir Brian Flowers (Chrm.), Nuclear Power and the Environment. Sixth Report of the Royal Commission on Environmental Pollution, Her Majesty's Stationery Office, London, 1976.

25. G. Hardin, "Living with the Faustian Bargain." Bulletin of the Atomic Scientists 10:25-29, 1976.

26. E. D. Gray, Comments made at the Conference on Public Policy Issues in Nuclear Waste Management, 1976 (see n.3).

27. P. Slovic, "Psychological Factors in the Perception and Acceptability of Risk: Implications for Nuclear Waste Management." Paper presented at the Conference on Public Policy Issues in Nuclear Waste Mangement, 1976 (see n. 3).

28. M. Willrich and T. B. Taylor, Nuclear Theft: Risks and Safeguards. Ballinger, Cambridge, MA, 1974.

29. B. Cohen, "The Potentialities of Terrorism: Plutonium is an Overrated Weapon for Terrorist Use." Bulletin of the Atomic Scientists $6: 34-35$, 1976.

30. W. H. Millerd, Nuclear Energy: The Morality of cur National Policy. CSPI Energy Series V, 1974. Center for Science in the Public Interest, 1779 Church Street, N.W., Washington, DC 20036. 
31. B. Sieverling, "Government Energy Savings Slip." Seattle PostIntelligencer 114:1, 1977.

32. A. W. Murphy, ed., The Nuclear Power Controversy. Prentice-Ha11, Inc., Englewood Cliffs, NJ, 1976.

33. M. Willrich, "Institutional Arrangements for Radioactive Waste Management." Paper presented at the Conference on Public Policy Issues in Nuclear Waste Management, 1976 (see n. 3).

34. G. I. Rochlin, "Nuclear Waste Disposal: Two Social Criteria." Science 195:23-31, 1977.

35. K. Garlid, "Radioactive Waste: A Basic Issue in the Safety of Nuclear Power." The Trend in Engineering, pp. 12-21, October 1974. 


\section{CHAPTER III}

SOME ETHICAL CONSIDERATIONS REGARDING

RADIOACTIVE WASTE DISPOSAL ISSUES

It is widely believed that technologies for the production of electrical power through the use of fissionable materials such as uranium and plutonium offer a number of benefits to mankind. The basic benefit is the availability of electrical energy to sustain or enhance our quality of 7 ife. Other benefits include reduced reliance on hydrocarbon power sources, reduction of certain pollutants, and--under certain circumstances--cost savings. It is evident, however, that some observers believe that these technologies offer profound moral and ethical dilemmas for mankind, $(1,2,3)$ and that before further public investments in these technologies are made, an ethical analys is should be undertaken of these moral issues.

This chapter examines in some detail one such moral issue--how to assess the appropriateness of one generation imposing risks and conferring benefits on another--and outlines a number of other moral problems that nuclear waste management raises. For purposes of this analysis, a moral problem is taken to be one in which the interests of different individuals come into conflict in the absence of a clear and mutualiy agreed-upon rule for deciding whose interests are to prevail; or, as Frankena stated, "Most moral probiems arise in situations... where one moral principle pulls one way and another pulls the other way." $(4, p .2)$

Before we turn directly to the issues, it will be usefur to discuss briefly the nature of, and the relation between, ethics and morality. Ethics is systematic thinking about morality. As physics is the science of matter, so ethics is the science of morality. Morality can be thought of as a kind of "grammar of conduct." Just as one attempts to speak using rules of grammar, so a moral person attempts to live following certain rules of conduct. These moral rules might specify, for example, what kinds of behavior are forbidden and what kinds of behavior are obligatory.

In any careful consideration of moral issues, one of the most important distinctions to be made is between "positive morality" and 
"critical morality." A positive morality is a "morality actually accepted and shared by a given social group." $(5$, p. 20) This is determined by tradition or culture and is generally internalized in the form of a conscience or superego. (4) A critical morality, on the other hand, is a set of moral principles that has been developed as a result of a sustained effort to create a rationally acceptable moral outlook. This is achieved when a person has a valid rational basis for his or her positive morality.

The positive morality of one person or group may differ from that of another person or group. Similarly, critical moralities may differ among individuals or groups. Therefore, whether two people agree that something is or is not moral depends upon (a) how the two people understand the facts of the case, and (b) if the two people hold a compatible positive or critical morality. The comparison and evaluation of the reasons in support of critical moralities make it possible in some cases to resolve moral differences by rational means. In the following discussion, some very tentative steps are taken toward establishing some critical moral principles concerning nuclear waste disposal.

\section{INTERGENERATIONAL ISSUES}

The fission process gives rise to two groups of radioactive materials--fission products and actinides. Most fission products decay to very low levels of radioactivity in about 700 years. ${ }^{(6)}$ However, the actinides--assuming that the plutonium-239 isotope is representative-will decay to very low levels in about 500,000 years. The longevity of fission-product and actinide radioactivity therefore causes concern about risks and potential costs to many generations in the future.

Other technologies that have been or are currently being employed may also impose risks or costs on future generations. Examples of these risks are the introduction of large quantities of carbon dioxide into the atmosphere and the consumption, as fuel, of fossil materials that have many uses. Nuclear waste disposal, then, is not unique in having intergenerational effects. This fact makes the study of intergenerational obligations more important, not less, because whatever principles are formulated to cover nuclear waste should shed considerable light on other obligations to the future. That is, the principles that are 
formulated are general enough to cover all technologies that can affect future generations, and they should be applied to these technologies as well as to nuclear power. This application to all technologies, however, is beyond the scope of this chapter.

There are at least two major factors that make the intergenerational aspect of the radioactive waste disposal issue problematic from an ethical point of view. First, intergenerational effects imply impacts on persons who, since they are not yet born, are unable to assess their willingness to undergo the risk and are unable to appraise how the risks might be mitigated and/or traded off against benefits for themselves or others. This situation is markedly dissimilar from that in which living persons find themselves-at least those living in countries that permit the public to participate widely in the decisionmaking processes. That the processes of participation do not work perfectly is well known, but in principle, at least, there are means for redress, for expression of concern regarding possible effects on one's interests, and for avoidance of certain risks. Future generations obviously have no such capacities.

With respect to the ability to appraise one's interests and how they might best be protected, people of future generations are similar to those whom our society has declared legally incompetent, such as minors and the mentally infirm. A set of institutions exists for protecting the legally incompetent from those who might either purposely or inadvertently exploit them. For instance, some other person or group is charged with the responsibility of acting as proxy, or advocate, for a person whose ability to represent his or her own interests is nonexistent or impaired. The policy implications of the similarity between these circumstances and those of future generations will be considered in more detail below.

A second feature that makes the problem of nuclear waste disposal an important moral problem is the knowledge of this generation that radioactive materials can impose risks on people yet to be born. We understand many of the health dangers that are associated with radioactive material. (It is at least worth speculating that those who first burned coal in the industrialization of England simply had no idea that 
they might be imposing a significant cost on future generations, if that is the case.) Indeed, many of the moral issues associated with the disposal of radioactive wastes also arise in connection with the consumption of, and related pollution from, hydrocarbon sources.

\section{INTERGENERATIONAL PRINCIPLES}

The following discussion sketches some principles by which judgments may be made concerning the legitimacy of imposing on future generations risks associated with radioactive waste disposal. It is important to note that the principles do not suggest what one ought to do without relevant factual and theoretical information. It is hoped that these principles can provide a standard to assist in (a) forming judgments concerning which types of disposal of existing wastes best discharge our responsibilities to future generations, and (b) appraising the legitimacy of producing additional wastes.

It must be noted that there is no well-worked-out theory of justice between generations. Because we have no general theory of intergenerational justice, the principles of this section must be regarded as tentative and essentially ad hoc. The principles discussed below can be checked against our other moral practices, which constitute certain evidence on their behalf (see Rawls (7) for a description of this method of reflective equilibrium). Since there is no way to check their "fit" with an overall theory, however, it would be a mistake to regard these principles as fully substantiated.

In particular, the principles that follow do not address the possibility that future generations might not exist at a11 or might be larger or smaller than the present one--considerations that would affect the principles' overall validity or their interpretation. Intergenerational saving--how much consumption we should forego in favor of future consumption--has not been considered. It is assumed, however, that there will be creatures more or less like human beings beyond the time (700 years) that fission products would be hazardous.

The storage and disposal of radioactive wastes raises the question of what risks we are morally permitted to impose--not only on present generations but also on those persons we shall never know. Two principles, along with an analysis of some examples to support them, are 
discussed below. The basic method followed is that of taking clear cases or examples of our obligations to the present generation and generalizing to future generations. (This "generalization forward" to the unborn might itself be justified by reference to other standards such as the equal moral standing of all human beings.) Although the two principles are stated in terms of risks and benefits, they have not been formulated using a utilitarian approach. (8)

Principle One: Satisfying preferences and imposing risks on others.

No generation can legitimately impose "serious risks" upon future generations unless "the benefits" that the imposing generation derives clearly outweigh the costs imposed upon future generations.

By "serious risks" we mean the risk of premature death in large numbers or significant health problems for many persons (e.g., production of large numbers of mentally retarded or malformed children, increased morbidity, etc.). By "benefits that outweigh" we do not mean, for example, marginal improvements in the standard of living if they accrue to the affluent. Indeed, we must be careful not to confuse factors necessary in the preservation of our way of 1 ife with steps to be taken to literally preserve this generation or a significant number of people in it. The present level of affluence simply does not constitute the only plausible and possible level necessary for human existence. For instance, we should not trade off aesthetic preferences for other people's 1 ives--at least uniess those whose 1 ives are placed at serious risk by such trade-offs have the option of declining to accept the risk.

Some additional examples will make this clearer. Suppose, for instance, it is decided to increase the production of electrical energy-by whatever means--by a very marginal amount, thus making it possible to produce and use more electrical appliances--e.g., electric blankets, electric toothbrushes, etc.--that contribute very marginally to the we11-being of this generation. If, in doing this, serious risks, as described above, were imposed on future generations, then such a practice would violate Principle One.

What is the case for such a principle? Consider a similar situation. How would we react to a trade-off within this generation that 
imposed serious risks on some to satisfy the mere preferences of others? If the people in this generation were (for purposes of argument) unable to assess their own willingness to take risks, and had some way of avoiding them, considered moral practices would rule out imposing such risks on them. To be sure, the burning of coal for purposes of generating electrical energy is used by a number of people to make very marginal improvements in their happiness. The mining of coal imposes substantial risks on the miners, but, at least in principle, the miners are in a position to assess their willingness to bear these risks in light of their other options. It would, however, be immoral to permit one person to force another to undergo such risks, except in cases of danger to the whole society--an argument that justifies coercion of persons in the military service. One person may not be involuntarily placed at risk to satisfy the whim of another. This was a basic consideration in the prohibition of slavery. The principle stated above simply generalizes this intragenerational case to intergenerational circumstances.

Note that Principle One does not, for example, include a determination of whether continued radioactive waste production is justified. Rather, it offers a standard by which such a determination can be made once relevant factual and theoretical information has been introduced. To apply the principle to a particular case, one needs both to accept it and then to load it with empirical information as developed within this report and as found elsewhere in the literature.

Principle One focuses our attention very sharply on the ambiguities involved in the concept of need. (9) The word "need" can cover the whole range of issues, from life-preserving measures (e.g., a blood transfusion) to assertions that we "need" something less vital (e.g., a new car). To the extent that radioactive wastes impose significant risks on future generations, radioactive waste production is justifiable insofar as it permits satisfaction of the first sort of need and becomes progressively less justifiable as we move toward the second.

The principle was stated in terms of "serious risks" to future generations in order to get to the root of the associated problems. The word "serious" could be relaxed or omitted so that the principle would say that we should avoid imposing any risks on future generations from 
which they would not benefit unless there would be very important benefits to the present generation. The more we weaken the word "serious" in the above principle, the more stringent the moral requirements of the principle become, because this weakening tends to rule out the imposition of a larger and larger universe of risks. Obviously, the two parts of the principle are inversely related to each other. The more the present generation benefits and the less future generations are placed at risk, the more justifiable the policy.

In applying this principle, moreover, it must be kept in mind that the word "benefit," like the word "need," has a number of different senses. The benefits derived from avoiding anarchy or worldwide recession have greater moral standing than those derived from, say, an increase in the proportion of air-conditioned rooms. In general, benefits associated with health and safety are morally more significant than those that merely satisfy preferences, because, to cite only one reason, we cannot satisfy preferences if health and safety are absent or impaired.

A possible objection should be considered: we do not know that future generations will regard the same things as we do to be risks. Human practices and tastes change over time; hence we do not know how to predict what our remote successors will value. Consequently, it could be argued that Principle One depends on knowing something that we cannot know, and thus should not be considered binding. But this objection overlooks the fact that the principle has been fleshed out in terms of goods that we may assume that any rational sentient creature will want. They include life, absence of morbidity, and the like--things that any creature even remotely like ourselves will want no matter how his tastes or practices differ from our own. Goods that rational creatures will always want have been called "primary goods" by Rawls. ${ }^{(7)}$ As a result of making this distinction, we relieve ourselves of the problem of having to predict the expectations and preferences of temporally remote civilizations. Hence the principle stated above might be restated as:

Principle One-A: Satisfying preferences and threatening the health and safety of others.

No generation can legitimately place the health and safety of future generations at risk, unless such practices are necessary to preserve the health and safety of this generation. 
Obviously, assessing the likelihood of risk and estimating the number of individuals possibly affected by it would need to be spelled out in applications of this principle.

This principle is similar in some respects to one put forth by Rochlin: ". . present generations should act so as to minimize the amount of irreparable harm that could occur as a result of present decisions."(3, p.26) Rochlin's principle, however, does not allow determination of when and to what extent irreparable harm could be imposed. For instance, the best way to minimize irreparable harm (while still preserving the species) might be to eliminate $50 \%$ of today's world population by some means other than natural death. However, few would advocate this course of action. Hence, it would appear that we do not have an unqualified obligation not to leave future generations worse off. Perhaps Rochlin ${ }^{(3)}$ realized that counterexamples of this sort could be offered when he weakened his principle (and moved it toward Principle Two given below) to read: ". . . to act so as to minimize exported risks, particularly when to do so imposes no great burden upon the present, is the minimum ethical requirement." $(3, p .26)$

\section{Principle Two: Bearing minor costs to preserve health and} safety.

If the present costs of some policy are minor or relatively trivial, and bearing them will avoid serious risk to the health and safety of future generations, then we ought to bear them.

This principle can be derived by asking whether we ought not to do such a thing for any persons presently existing and then to see if there is any reason for distinguishing our contemporaries in terms of moral importance from those in future generations. For instance, Singer (10) has suggested that we are not morally permitted to forego saving a drowning person on the grounds that we don't want to waste our time or to get our clothes dirty.

Stating the principle in terms of health and safety of future generations avoids some "slippery slope" problems of trading off marginal benefits between generations. This formulation also mitigates, in part, the previously noted shortcoming of our approach in not addressing the problem of intergenerational savings. It does not direct our 
attention to how much consumption we should forego in favor of their consumption; but rather, what investments we should make so that our successors may live and not experience avoidable morbidity.

The principle would require, for instance, that if there are rather minor costs in substantially reducing the risks to future generations (through certain storage and disposal techniques), then the costs ought to be incurred. If, for example, through relatively minor costs of research and development, a process could be developed to change longlived radioactive material into a shorter-lived or nonradioactive form, then we ought to pursue that line of research--unless very low-risk alternatives could be devised.

But what about cases where the development and use of a process such as transmutation are very expensive and the prospects of avoiding premature death and morbidity are significant? A variation on the principle could be formulated, holding that money costs could not be traded off against demonstrated risks to health and safety of large numbers of people.

Principle Two and possible reformulations of it are not of much assistance either where lives of this generation are traded for those in the future or when very large money costs are incurred to slightly lower an already very low risk. If circumstances meet either of these descriptions, further research and refinement or reformulation are necessary.

At the beginning of this chapter we noted that future generations bear important similarities to presently living persons who are incapable of understanding and/or protecting their own interests. As a rule, individuals are appointed to act on the behalf of those people. The same considerations that support protective measures in these cases appear to support them in the case of future generations, where contemplated policies could impose substantial risk on them. How such a "proxy for the unborn" would be institutionalized is, of course, a complicated issue. Whatever institutional form this proxy takes, its major role would be the assessment of risks and benefits of certain practices on future generations.

Though the principles formulated above should help to clarify our obligations to future generations for as long as the wastes remain 
dangerously radioactive, their formulation does not exhaust our responsibility for three reasons. First, the principles--as noted above--are ad hoc. Indeed, an early task of any such proxy group should be an inquiry into the possibility of constructing a theory of intergenerational justice, at least with respect to health and safety issues. Second, even if we were able to accord some degree of certainty to these or other principles, their application to particular cases would not always be clear even with considerable deliberation. Third, the press of events will often mean that the principles themselves will not be scrutinized at appropriate times--at least not until institutional mechanisms are set up to insure such scrutiny. Without such an institution it is not easy to see how we can give effective expression to Edmund Burke's sentiment (Reflections on the Revolution in France) that "society is indeed a contract... a partnership not only between those now living, but between those who are living, those who are dead, and those who are to be born."

We should also note that for both inter- and intragenerational issues what is in the interest of any given nation or generation is not necessarily in the interest of all. Consider an intragenerational example. Insofar as a few nations become dependent upon nuclear technology, methods of disposal that are relatively safe in the short run could well be the dilute and disperse technologies that are employed in other arenas. To the extent that the dilute and disperse technologies are inexpensive, it is in everyone's economic interest to utilize that method. But since the quality of the world's environment could be adversely affected, the collective well-being is undermined by dispersal. For these reasons, internationalization--either in terms of actual waste disposal or in terms of agreements about disposal with enforcement procedures--seems to be a matter of the highest priority.

\section{INTRAGENERATIONAL ISSUES}

A number of other questions have been raised concerning the moral implications of nuclear waste disposal. As noted in the beginning of this section, we have concentrated our attention on intergenerational issues. This section would be incomplete, however, if it did not 
address some of the issues that affect any generation producing nuclear wastes. The following offers at least tentative accounts of how some of these problems might be regarded from a moral perspective.

This discussion is not directed to the question of whether radioactive wastes should be produced on a large scale. The moral issues associated with such a decision can be evaluated by applying the two principles discussed above across space rather than across time. The current discussion focuses on a number of moral issues that could arise with regard to radioactive waste management if nuclear energy becomes a primary source of energy. Since the issues are discussed very briefly, we have indicated from time to time where we think inquiry could be helpful. Many of these issues involve equity considerations that have not yet been clearly addressed.

\section{Management Problems}

It is sometimes argued that nuclear power will give rise to a number of management problems, for example, regarding hazards of the power-generating site, loss of materials during transport, leakage of waste in the storage facilities, and accidents to transportation vehicles or storage sites. The effect of management decisions is to put people at risk involuntarily, with the possibility that they will receive no compensation. Several mechanisms, such as insurance and the tort liability system, exist for handling this differential risk with regard to radioactive waste management.

\section{Insurance}

There are insurance mechanisms to compensate persons who are placed at risk and are involved in transportation accidents. Accidents occurring at reprocessing facilities are covered by the insurance provisions of the Price-Anderson Act. However, compensation mechanisms are not clear-cut for those injured or placed at risk by radioactive releases at final waste repositories. The Price-Anderson Act is not applicable in such cases, and it is questionable whether such persons could sue for compensation under the Federal Tort Act. Compensation in this situation must be studied carefully, and steps should be taken to guarantee an equitable outcome. 
Tort Liability System

Is the tort liability system responsive to the kinds of issues raised by radioactive waste management systems? It may be very difficult to say what constitutes an injury or who is at fault. If, for example, the existence of plutonium in the environment reduces the average life expectancy by a few months and it is impossible to prove whether any given death was so caused, it would be very difficult to assign fault and to find mechanisms and principles for compensation.

However, these same issues pertain to the release of any toxic substance into the environment. Since the problem is not unique to radioactive wastes, we should examine whether the tort system ought to be replaced by a no-fault system or some other approach in cases where establishing a causal connection is difficult. The task of defining what counts as a compensable event is an area in need of serious study. Source of Reparation

No matter what mechanisms are available for rectification of injuries or property damage, these mechanisms are meaningless unless there are assets available to draw on when compensation is required. It would thus appear appropriate to focus attention, from an ethical point of view, on the characteristics of an insurance system that would be needed to back the development of a new technology such as radioactive waste management. Studies are needed to explore the questions of who should pay the premiums and how incentives can be constructed to minimize the prospects of injury.

Dislocation Issues

Risk and Equity, in Chapter II, discussed the issue of geographic dislocation among the population for waste storage facility siting and the problem of states storing nuclear wastes generated in other states. These issues, in contrast with management issues, involve purposeful policies that the government may pursue that differentially affect persons in the population.

Two types of people are affected here: (a) those who are actually dislocated from their land, and (b) those who are not dislocated from their land but who are adjacent, say, to a storage site. In the case of 
the first group, the normal procedures of eminent domain could be relied upon, using the compensation principles built into such requirements.

The case of those persons located adjacent to sites involves complex issues concerning whether a "taking" has occurred. This is an area of the law in which a number of people have urged substantial changes in the circumstances under which one could obtain compensation for ioss of value where land is not taken in fee simple. (11) These changes are just beginning; for instance, methods are now available for evaluating economic damage due to aircraft noise.

Along with the consideration of whether a taking has occurred is the fact that people iiving, say, near a waste repository be involuntarily placed at risk for benefits that others receive. It has been said that this dislocation of risks and benefits requires special ethical considerations for those who experience risks or costs for the larger good. Several possible considerations need further study: (a) whether the persons at risk must give informed consent (changing the risk from involuntary to voluntary) and, if so, what form the consent should take; (b) whether compensation should be provided in this case for those who take risks for others, and, if so, what form the compensation should take; and (c) whether adequate means exist for those placed at risk to effectively participate in the decisionmaking process, and, if not, what measures are required.

\section{Civil Rights Issues}

Will radioactive waste management endanger civil rights and civil liberties? This concern was discussed in Chapter II under Issue 6 . In this discussion it was pointed out that there are a number of ways to prevent the diversion of plutonium, say, for terrorist purposes. These can include the use of security clearances for industrial workers; tight security during storage, transport, and disposal; and technological processes such as the once-through fuel cycle or the uranium-only recycle.

It is possible, however, that safeguard forces in the future may depend upon the abridgment of civil rights to protect the population against terrorism. In principle, such abridgement can be prevented or ended by the constitutional barriers that exist to prevent such abuses. 
That there may be certain abuses in connection with a technology does not prove that there is anything immoral about the technology itself. To show that radioactive waste management was morally problematic from this point of view, one would have to show that it intrinsically involved such abuses, or had a strong tendency to induce them.

Distribution of Wealth Internationally

Another question that is frequently raised about nuclear power is whether it will widen the disparities of wealth between the so-called third and fourth world nations and the industrialized nations. The role of radioactive waste management and related technologies in the distribution of wealth internationally is not clear at this time. (12) The distributive question is a social and technical issue concerning the most effective means of alleviating poverty abroad--radioactive waste management is but one small part of the whole issue. This issue is further complicated by the fact that no good theory of justice between nations has been worked out. There is an obvious need for more work in this area.

\section{Other Issues}

Other issues that have intragenerational moral considerations were discussed in Chapter II. Issue 7 , regarding the use of conservation and of alternative methods of power production before going to nuclear power, has an important moral component. If, for instance, we wait until all alternative methods have been tried, and if these methods fail, we might find ourselves far behind in nuclear power development. This situation could have a significant effect on the U.S. economy, as well as on future generations. These moral considerations, which concern an optimal investment strategy, must be addressed when attempts are made to resolve this issue.

These considerations also apply to acting in the face of uncertainty. For example, if we wait until all uncertainty is resolved-which will probably never happen--then we might find ourselves in a situation where it is too late to act effectively. On the other hand, if it is possible to resolve some of the uncertainty in the near future, then it is perhaps better to defer the decision for a time. There are obvious trade-offs here involving moral considerations that need to be addressed in the decision-making process. 
1. A. V. Kneese, "The Faustian Bargain." Resources, No. 44, Resources for the Future, Inc., pp. 1-5, September 1973.

2. Conference on Public Policy Issues in Nuclear Waste Management, Chicago, IL, October 27-29, 1976.

3. G. I. Rochlin, "Nuclear Waste Disposa1: Two Social Criteria." Science 195:23-31, 1977.

4. W. K. Frankena, Ethics. Prentice-Ha11, Inc., Englewood Cliffs, NJ, 1963.

5. H. L. A. Hart, Law, Liberty, and Morality. Vintage Books, New York, NY, 1963.

6. D. J. Rose, "Nuclear Eclectic Power." Science 184:351-359, 1974.

7. J. Rawls, A Theory of Justice. The Belknap Press of Harvard University Press, Cambridge, MA, 1971.

8. J. J. C. Smart and B. Williams, Utilitarianism For and Against, Cambridge University Press, 1973.

9. D. Callahan, Comments made at the Conference on Public Poticy Issues in Nuclear Waste Management, 1976 (see n. 2).

10. P. Singer, "Famine, Affiuence, and Morality." Philosophy and Public Affairs, Spring 1972.

11. The difficulties with a position like this are well spelled out in F. Michelman's "The Ethical Foundations of the Just Compensation Law" and The American Law Institute Model Land Development Code, The Taking Issue, and Private Property Rights by P. G. Brown

12. World Councit of Churches, "Report on Nuclear Energy." Anticipation $21,1975$. 


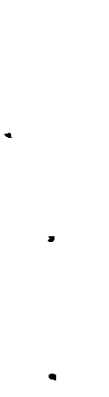




\section{CHAPTER IV}

\section{INSTITUTIONS IN LONG-TERM NUCLEAR WASTE MANAGEMENT}

\section{INTRODUCTION}

Disposal of radioactive waste materials from the commercial nuclear power program presents a problem for public officials and citizens who must make choices about methods by which these waste products will be isolated from the biosphere for an indefinite period of time. Because of the long half-lives of several elements in radioactive wastes, many of these materials must be isolated from the biosphere for periods of thousands of years. The waste materials must be placed in some repository or storage location in the next 10 to 25 years. Thus the choices that are made about repository location and the geologic media in which these wastes will be isolated are choices that have potential applications for the people who will live several thousands of years from now.

A number of concerns have been raised regarding the role that human institutions may have to play in the long-term management of nuclear wastes. Controversy exists concerning, first of all, the need for any human institutions to be involved in long-term management; secondly, there is substantial uncertainty about whether human institutions could actually carry out any functions that might be required of them over the long term.

The major objective of this chapter is to provide a framework for thinking about institutional issues that may be involved in the longterm management of nuclear wastes. An attempt has been made to identify organizational functions that might be needed to insure the integrity of a waste repository over several centuries.

It is important to emphasize the speculative nature of such discussions. Historical examples of the behavior and durability of human institutions are the only data that can be applied to the speculations about the potential future stability and performance of institutions. However, it is clearly impossible to predict what the world will be like 50 years from now, let alone in several centuries. Thus, the historical 
examples, while they may be intriguing, cannot be accepted as a clear guide to the future.

The purpose of this chapter is to address the questions raised by a number of critics and a number of supporters of nuclear technology concerning both the need for human institutions in the long-term management of nuclear wastes and the likelihood that such institutions might perform as required. This discussion is intended to ventilate some of the major issues in order that some better determinations may be made as to whether some of the points raised are as serious as they seem on the surface.

\section{BACKGROUND}

\section{Public Concerns}

A number of concerns have been raised regarding the institutional aspects of long-term nuclear waste management by critics of nuclear power, supporters of the technology, and concerned citizens. The questions and concerns are often open-ended, contradictory, or inherently unanswerabie. Some of the more salient of these concerns are:

1. Can we have any assurance that societal institutions will last long enough to carry out the necessary management activities to insure the safety and integrity of waste repositories?(1)

2. Conversely, is there a need for institutions to carry out surveillance of repositories or to conduct environmental monitoring of repository sites? (2)

3. Can we have any assurance that at some remote time in the future, people will not enter repositories, either deliberately or inadvertentiy, not fulty understanding the dangers of the materials contained therein?(3)

4. Is there any need (and is it even desirable) to preserve records on these repositories over tens of centuries? ${ }^{(4)}$

5. Will the institutions set up to manage the waste repositories be durable enough to withstand changes in political regimes or other societal changes?(5) 
6. Are durable institutions necessary to insure protection of future generations from radiological hazards?(6)

7. Will the institutions set up for waste management operate as they are supposed to? Will they be competent? How will such institutions be regulated or controlled?(7)

8. How will the financial costs of the waste management program be borne? $(8)$

General Characteristics of Waste Management

A number of general characteristics relevant to nuclear waste management should be kept in mind when thinking about institutional issues in long-term management of nuclear wastes:

1. Temporal separation of benefits and burdens. The time in which benefits associated with nuclear power are enjoyed is different from the time periods when the wastes must be managed. In this regard, the Nuclear Regulatory Commission (NRC) Task Force on Goals for Nuclear Waste Management noted:

The first is the period during which society is actively involved in the production of nuclear power. The second period extends to the time when society ceases to take an active interest in the management of nuclear wastes. The final period begins when, due to societal discontinuity or simple lack of concern, society abdicates its responsibility for active management of nuclear wastes. (9)

This first period has been estimated to be approximately 100 years. (10) Light water reactor (LWR) wastes, including decommissioning wastes, would extend 5 to 20 years after the LWR nuclear fuel cycle has ceased to be used.

2. Geologic disposal. At present the most frequently discussed waste disposal alternative is deep geologic disposal. The institutional analysis in this paper uses geologic disposal as the base case. The institutional problems might be different with seabed or outer-space disposa1.(11)

3. Radioactive decay. Wastes buried in geologic formations will undergo natural radioactive decay. The highest levels of 
radioactivity and thermal release will occur in the first century after the waste materials have been placed in the repository. (12) Between 100 and 700 years after the wastes have been emplaced, fission products in the waste will decay to low levels. (13) Roughly 1000 years after emplacement, the bulk of the nuclides will have decayed to low levels. However, long-lived actinides, and some other elements (e.g., Te-99, I-129) will continue to be radioactive for many more thousands of years. (14) Thus, using human time scale, these few elements are permanently radioactive. Accordingly, three general time periods are distinguished: (a) the first 100 years after waste emplacement, (b) the period 100-700 years after emplacement, and (c) the perpetual stage from roughly 700 years after emplacement until the time the waste is no longer toxic. (15)

4. Waste form. The nature of the wastes left in repositories will be dependent upon whether nuclear fuel is reprocessed, or whether spent fuel elements are directly interred with no reprocessing.

5. Geologic integrity. The primary means for assuring that radioactive materials are permanently isolated from the biosphere will be the selection and use of a repository located in an optimal geologic site. Human institutions are not expected to provide anything but a marginal increment in safety.

6. Events that could compromise a repository. Assuming that deep geologic disposal is the method used to isolate wastes from the biosphere, it is appropriate to consider how such a repository might be breached. The NRC identified four major classes of events that might lead to a major release of radioactivity: (16) (a) natural rapid events, such as meteors, storms, and earthquakes; (b) natural geologic events, such as erosion, faulting, and subsidence; (c) repository-caused geologic events, such as subsidence and thermal effects; and (d) human actions, such as war and sabotage.

Human institutions might enhance safety by accurately predicting the occurrence of the natural events listed above, and in responding to 
them to reduce consequences. Control over these massive events is not likely.

Human actions directed at the repository are quite difficult to predict; thus, considerable uncertainty is associated with the probability and consequence of human actions that may directly or indirectly lead to radioactive release.

Human actions that might produce a release have been grouped into three categories: $(17,18)$ (a) major catastrophic events, such as nuclear war, plague, or famine; (b) direct action against the repository, such as sabotage, drilling and exploration, and excavation; and (c) lapses in monitoring, such as being unaware of a low-level breach.

Thus it appears that human institutions can theoretically function to predict and react to natural events, and can function to prevent human actions that could lead to a release.

A FRAMEWORK FOR EXAMINING THE PROBLEM OF INSTITUTIONS IN LONG-TERM MANAGEMENT

To examine the institutional requirements in long-term nuclear waste management, three sets of factors appear pertinent for this discussion: (a) the functions that can or should be performed by the institutions, (b) the perceived need for these functions, and (c) the likelihood that the functions will be performed at any given point in time.

\section{Functions that Might Be Performed}

Three general categories of functions might enhance the safety of a waste repository.

1. Control and management--including monitoring of security and physical integrity, performance of routine physical plant maintenance, and maintenance of a staff of people qualified to carry out technical tasks at the disposal site.

2. Monitoring--including observation of seismic, thermal, and radiological conditions to detect any releases or significant changes in site integrity. 
3. Information transfer--including maintenance of records and data about the repository and its contents. Such information would be needed to effect repair of a site, to warn future generations about the dangers of the wastes, and to prevent an intrusion into the repository at some time in the distant future.

Carrying out functions 1 and 2 might help to insure that potentially dangerous natural geologic events could be predicted. Some human actions directed at the repository might also be prevented. Carrying out function 3 would help in tailoring responses to any compromises of the repository.

Time Period

The management of nuclear waste can be divided into three major time periods based on thermal and radioactive decay of materials in the waste. (19) Based on considerations given in the background section, the discussion will focus on three phases:

- Phase 1: The first 100 years after removal of spent fuel from the reactor (0-100 years).

- Phase 2: 100-700 years after removal from the reactor.

- Phase 3: 700 years and beyond.

The bulk of radioactive decay and thermal release occurs during the first 100 years after fuel is removed from the reactor (Phase 1). During Phase 2, fission products continue to decay to inert levels. At the start of Phase 3 , only the long-lived elements, which constitute a small portion of the original waste, remain substantially radiotoxic. For all practical purposes, however, the waste materials still contain significant levels of radiotoxic elements and, for the sake of this discussion, should be considered potentially hazardous to humans.

\section{Perceived Need for Functions}

As noted above, there is some disagreement about the need for longterm institutional involvement in waste management. The basic concept of geologic disposal is to reduce, and ideally, eliminate, the need for human institutional functions in the long term. Nonetheless, one has to exercise some judgment about such needs. 
Likelihood of Performance

While one may perceive a need for an institutional function (such as environmental monitoring), one might also perceive that the likelihood of the function being performed is very low or, conversely, very high.

It is important to keep in mind that these judgments of need and likelihood are necessarily time-bound and that these perceptions of the needs and likelihoods will vary among concerned individuals both in this generation and between generations. Dramatically different perceptions of the problem in the future would probably lead to deliberate changes in functions for long-term management.

The four variables of this analytical framework are summarized in Table 1. There are no entries in the cells because of lack of agreement on the two variables of need and likelihood. The reader is encouraged to fill in the level of need or the value of likelihood associated with each function and time period. Questions to be considered, for example, might include: Does the need for active control and management decline over a time period, as some would suggest? What is the likelihood that information about the site (if needed) would be available in Phase 3 ?

TABLE 1. Analytic Framework for Long-Term Institutional Involvement in Waste Management

\begin{tabular}{|c|c|c|c|}
\hline \multirow[b]{2}{*}{ Functions } & \multicolumn{3}{|c|}{ Time Period } \\
\hline & $\begin{array}{l}\text { Phase } 1 \\
\text { (Closure to } \\
100 \text { Years) }\end{array}$ & $\begin{array}{l}\text { Phase } 2 \\
(100 \text { to } \\
700 \text { Years) }\end{array}$ & $\begin{array}{l}\text { Phase } 3 \\
\text { ( } 700 \text { Years } \\
\text { and Beyond) }\end{array}$ \\
\hline \multicolumn{4}{|l|}{ Need for: } \\
\hline \multicolumn{4}{|l|}{ - Control/management } \\
\hline \multicolumn{4}{|l|}{ - Monitoring } \\
\hline \multicolumn{4}{|l|}{ - Information transfer } \\
\hline \multirow{2}{*}{\multicolumn{4}{|c|}{$\begin{array}{l}\text { Likelihood of performance: } \\
\text { - Control/management }\end{array}$}} \\
\hline & & & \\
\hline - Monitoring & & & \\
\hline - Information transfer & & & \\
\hline
\end{tabular}


The central concern of the present discussion is not the geologically engineered system, but rather the social organization that oversees this system. With respect to the requirements for maintaining an organization that can monitor and maintain a repository for a millennium, several factors seem to be most critical in assuring that needed functions can be carried out.

First of a11, it is necessary to consider the incentives that must exist for the U.S. government to maintain, for at least a century, the function of a waste management bureau or agency. The incentives that might exist within the organization to produce high-quality work and to carry out monitoring tasks should also be considered.

A second factor, often raised as an issue, centers on obtaining financing for the waste management program. This issue is one of several raised in discussions about transferring some burdens of the waste management program to future generations.

A third issue concerns the durability of institutions or organizations established to manage waste disposal sites. Clearly, no human organizations have ever existed for the length of time necessary for all radioactive wastes to decay to inert levels. There are several organizations, however, that have existed for sufficiently long time periods to observe the decay of most of the radionuclides from the LWR cycle. Again, the durability of functions of an institution is the key concern. Phase 1 ( 0 to 100 Years)

Phase 1 will clearly be associated with the highest level of institutional activity, since most or all of the human activity associated with waste disposal will take place in this period. The operations are highly complex relative to those of the other time periods because repositories will be built and filled in this phase. Possible operations might be:

1. Deep-geologic repository:

- Maintain frequent checks on monitoring instruments for seismic activity, thermal activity, etc., at or near the site. 
- Conduct periodic assessments of groundwater in the vicinity of the repository.

- Prevent unauthorized drilling in the exclusion area.

2. Deep-geologic repository (retrievable storage option). In addition to the above functions, there may be a need to:

- Maintain operating equipment for the repository.

- Maintain security against unauthorized entry.

3. Retrievable surface storage:

- Make frequent checks of monitoring.

- Inspect and maintain operating gear.

- Maintain security against unauthorized entry.

As noted earlier, Phase 1 is the period when the greatest amount of radioactivity will be present, and where any major design or engineering faults in the repository are likely to appear. Although it cannot be presumed that all design problems are likely to emerge early in the disposal management cycle, there is evidence from almost every other area of engineering work that most of the "bugs" in any system tend to appear early in the utilization period.

It should be noted that the need for functions listed above has not been clearly determined. Undoubtedly, judgments made during the operational life of the repository will determine the need for monitoring or maintenance functions. At this time, there is no way to guarantee that certain functions will be seen as necessary. Indeed, it is not clear that the present generation should in any way attempt to dictate future institutional behavior.

\section{Durability Considerations in Phase 1}

There are numerous examples of public and private institutions in the United States that have functioned effectively for periods of 100 years or more. There is a pronounced tendency for complex governmental institutions to grow or at least to stabilize once they are established, rather than to wither. As will be discussed below, the tendency toward bureaucratic stability has occurred within a context of reasonably stable political conditions. Where major political upheavals (e.g., wars or revolutions) have occurred, the bureaucracies that were a part 
of the old order did not generally survive intact, but some of their functions, nevertheless, did.

A brief list of some public and private organizations that have enjoyed an active operating life of 100-150 years follows:

- The U.S. National Bank System (1815)

- The University of Michigan (1817)

- U.S. Navy (1789)

- Standard 0ir Corporation (1870)

- The Amana (Iowa) Manufacturing Company (1840)

- The state governments of all states in the Union before 1875 .

Such examples illustrate that, in principle, complex functional organizations can exist for a century. It should be reemphasized that the survival of any given organization or selected group of organizations for 100-150 years does not provide a basis for presuming that an organization established today will survive for a similar period.

A critical factor in the resilience of some of these long-lived organizations has been the favorable and stable political system of the United States during the organizations' lives. Thus, when considering the potential longevity of a governmental institution, it is necessary to consider the possible impact on such an organization of major changes in the political system.

Two conditions could significantly affect the longevity of any given governmental organization. The first is a major political upheaval such as a revolution. The second is a less extreme form of major political change, such as a massive redirection of governmental energy policies or a fundamental change in the scope of governmental activities.

When the effect that either of these political changes might have on a waste management organization is considered, it seems probable that in any situation where the transfer of power occurs in an orderly manner, or the evolution of policy occurs in a series of small, incremental steps, the operation of a waste management organization would not be disrupted. Changes in management practices would probably be the result of reasoned judgment rather than purely political considerations. Management of nuclear waste is a practical problem for democratic, socialist, or pure authoritarian regimes. 
A situation in which the waste management system might be impaired would be one in which the U.S. government gradually deteriorated or collapsed, and all routine functions ceased. It is doubtful if such an extreme situation would occur outside the context of a nuclear war, massive plague, or famine. As noted earlier, if a nuclear war occurred, the danger posed by buried or entombed radioactive waste would seem smal1 compared to fallout from weapons. Plagues or famine might lead to the abandonment of monitoring and surveillance functions, particularly if the waste management staff were decimated.

\section{Incentives Considerations for Phase 1}

External incentives for preserving a waste management agency within the federal establishment could be expected for a number of reasons. No conclusive proof can be offered that such incentives will insure the perpetuation of a waste management agency. But again, the evidence and argument tend to support the notion that, if the U.S. government survives for the next century, there is a high probability that a waste management institution will be maintained.

Since the federal government must respond to the concerns of a majority of its citizens, there is reason to expect that a federal commitment on waste management might endure for a century. At present, a sizable segment of the general public is concerned about the safety of nuclear power. Even the staunch supporters of nuclear power base their support on a contingency of providing proper safety and waste disposal actions. There is little reason to believe that any substantial segment of the U.S. population today would tolerate wholesale abandonment of the principal organization that would provide safety from wastes stored in repositories. In this regard, it should be noted that the most avid supporters of nuclear power may well differ from their critics on the issue of "how safe is safe enough" (i.e., what level of security and surveillance is needed). But both opponents and supporters would agree that an "adequate" level of safety is required.

In a related vein, it seems likely that preservation and protection of the ecosystem will continue to be a major function of government for the foreseeable future. The present role of the Environmental Protection Agency (EPA) is an example. As greater pressures are placed on 
ecosystems from population growth, it is likely that the federal government will continue to play a major role in protecting the natural 1 ifesupport system. As a subset of this, it can be anticipated that a critical task will be to prevent harmful radionuclides from contaminating the biosphere. Thus, the necessary monitoring function may be performed by an institution (such as EPA) with a larger mission that society judges to be essential.

There has been much discussion about repository safety and security problems that might arise because of possible difficulties with providing adequate incentives to the work force in the repository's day-today operation to insure adequate quality control. Weinberg and others have raised the possibility of developing a nuclear "priesthood" that, because of its devotion to its task, and because of a screening process designed to recruit only exceptionally competent individuals, would provide an added increment of safety in waste management. (20) The argument for such an elite and dedicated group is that al though the tasks involved might require unusual vigilance, they would be of such a boring and routine nature that work of high quality could be assured only with unusually dedicated personnel. (21)

A highly skilled set of workers carrying out their duties with great precision in Phase I might well contribute to the perpetual security of the repository. It remains to be seen what increment of safety and security such a highly skilled work force might actually provide. It may be that the routine operations in a repository would be simple enough to trust to a far less elite work force.

\section{Financing Considerations for Phase I}

Yet another problem is the mechanism to be used in financing the waste disposal program, including long-term monitoring, surveillance, and maintenance. Current regulations require that ". . . industry will pay the federal government a charge which together with interest on unexpended balances will be designed to defray all costs of disposal and perpetual surveillance. . . ."(8)

A 1975 Environmental Protection Agency study by Rowe and Holcomb estimated that $0.05 \mathrm{mi} 11 / \mathrm{kwh}$ would be an appropriate charge to levy on nuclear-generated electric power to cover the costs of waste disposal 
and surveillance requirements up to the year 2000. Beyond that time, it is virtually impossible to develop any meaningful cost estimates. The major point is that during the operational phase of the LWR program, costs of waste management will be borne by the users of nuclear-generated electric power. It should be noted, however, that at this time some public utility commissions are reluctant to allow such charges to be included in electric rates. (23)

Provision of financial support for waste management institutions after LWR operations have ceased could be accomplished through diverting some money from operating revenues into some form of perpetual trust fund. This trust fund could be established with its major investments in land and other real property that are unlikely to lose value over centuries. The accrued interest of the perpetual care portion of this trust over 70 years might pay for surveillance well beyond 100 or 200 years.

Perpetual trusts are not unusual; a number of trusts have been established that have existed for 100 years or more. Provided that no massive economic collapse occurs, there is reason to believe that if a trust is set up to pay for waste management operations, it may operate effectively for a century, and perhaps longer.

One difficulty that might be encountered in presuming that a trust would operate as intended is that should government policy change, the funds might be tapped for purposes other than waste management. It is conceivable that, if at a later time the public felt that the risk from nuclear waste was infinitesimal, the funds derived from the trust might be shifted to other uses.

Phase 2 ( 100 to 700 Years)

In this phase the fission products continue to decay at an exponential rate. After about 700 years, the total radiation will have declined to a very low level. At that point, the repository's contents would still be potentially hazardous but much less so than during Phase 1 and the first half of Phase 2 .

During Phase 2 the government may maintain some organization with the task of carrying out monitoring and security functions, as well as 
the preservation of technical information about the site and its contents. The necessary tasks might include periodic monitoring of the site, occasional geophysical surveys of the site to determine its integrity, and preservation of technical records about the repository.

Again, decision makers 200 years from now may feel that such monitoring activities are unnecessary, and abandon surveillance altogether. The integrity of the site would be dependent on geologic isolation, not on human maintenance.

To evaluate the possibility of accomplishing any monitoring activities over a period of 600 years or so, it seems appropriate to again consider the likelihood of maintaining an organization to do monitoring work, the incentives for carrying out any required activities, and the means for financing such an organization over such a time period.

When cast in terms of human social and political history, 500 to 700 years is an extraordinarily long time. It is clearly impossible to predict what civilization may be like so far in the future. Historical examples, however, can reveal whether similar feats were ever accomplished before.

\section{Durability Considerations in Phase 2}

Whether a waste management bureaucracy charged with surveillance duties is deemed necessary during Phase 2 is impossible to predict. It is also impossible to predict whether any bureaucracy would survive for that period of time.

Some organizations have survived to the present day from origins dating back 200 to 1000 years. Again, their survival cannot be used as a basis for presuming that an organization established in present times would be able to survive for an equally long period. Rather, these cases indicate that some organizations have been able to persist for these time periods despite social and political turmoil. Examples of such organizations are:

- Harvard University.

- The English polity.

- The Roman Catholic church.

These institutions are considerably more complex than the organization that would be required to monitor and oversee waste management 
sites. The waste management organization could quite literally be compared to a single specialized department in any of the venerable institutions noted above. Thus, it may perhaps be more appropriate to examine the longevity of component departments within each of the organizations listed above.

Within each of these institutions there are specialized departments whose functions have retained substantial continuity across several centuries. In England, the tax and land records can accurately trace property holdings back to the Norman conquests. Various monastic orders in the Roman Catholic church have carefully recorded and preserved the complex body of church doctrine, practice, 1aw, and history for over a millennium. The critical point of the example is that although the form of various practices may evolve over time, the specialized functions (practices) and the body of critical information needed to perpetuate specific practices have, in some cases, been maintained through several centuries.

\section{Incentives Considerations for Phase 2}

If one assumes that the external incentives for maintaining surveillance of the waste management organization would be the same in Phase 2 as they were in Phase 1, then the government would presumably retain both an interest and a commitment to protect the health and safety of the general public. Exactly how this commitment would be translated into action is impossible to say. One thing is certain: the government in power at the time will make its own policy decisions about what levels of monitoring and security are to be in effect at waste disposal sites. A future government may decide to reduce or abandon surveillance; exhume high-level waste (HLW) and send it into space; utilize the waste as fuel, or maintain monitoring and security at a high level. If a technologically sophisticated society exists during Phase 2, the government will be able to exercise its own judgment about the risks posed to its citizens by the nuclear waste repositories, and to take action commensurate with the evaluation of these risks. However, a technologically naive society (which could exist in the future) would be much less able to exercise these options. 


\section{Financing Considerations for Phase 2}

Financial viability will depend in part on the success of any investing done during the active phase of waste generation, and it wi11 depend in part on the commitments that contemporary governments are willing to make to the waste management effort if Tong-term investments do not prove adequate to support the program. The financial viability issues being discussed are those of an organization that will begin its existence some 200 years (roughiy the present age of the United States) from this writing. The best available precedents on which any such projections might be made are provided by European financial institutions. The limitation of predictions based on historical projections must be borne in mind in this discussion.

Phase 3 (700 Years and Beyond)

With respect to Phase 3 of waste management--perhaps as remote from present-day 1 ife as the Norman conquests of England in 1066, and extending far beyond--discussion of human institutions becomes totaliy speculative. Human institutions or surveillance at this stage can be reduced somewhat from the earlier "active" periods, as the contents of the repository have decayed to the point where they are roughiy as radioactive as natural uranium ore deposits. About all that might be required would be to:

- Mark the site and indicate the nature of the contents.

- Conduct periodic monitoring and geophysical analyses to determine integrity.

In Phase 3 , the waste management problem can be described in somewhat different problematical terms. There is little likelihood that measures taken in the present could ensure the survival of an organization for such a long time period. Therefore, the concern of people in the present is to consider the need for, and Tikelihood of, preserving data and technical information that would permit civilizations existing a millennium from now to cope with potential problems posed by the contents of the repository.

After 700 years, the levels of radioactivity in repositories wil1 have deciined to such a point that monitoring and surveillance activities may then be judged to no longer be required. A dilemma arises in 
this case, for which the solutions are mutually exclusive. One argument is that it is absolutely necessary to preserve, in some comprehensible form, records and technical information about the site and its contents. This is seen as one way to enhance the safety of future generations. However, the opposite position can be taken: if the site is in no way identified, any human intrusion would be accidental, and perhaps less likely than if the site is identified.

For the moment, we shall assume that it is deemed desirable to try to communicate technical information to future generations. The question then remains--is there any reason to believe that communication of such information could be done? Clearly, it is impossible to provide definitive answers to the feasibility of transferring information over such enormous time spans. But it may be useful to think about what specific information should be communicated, and how such communication might be accomplished.

Communications can be hierarchically arranged from the most elementary avoidance warnings to more complex data sets. The most primitive would consist of simple site markers, using universal symbols, designed to warn of danger.

The waste disposal site would most likely be backfilled and sealed at some time shortly after it was full. Each of the access shafts and disposal cavities would be filled with rock, cement, or spoils from the original excavation. Once this was completed, other identifying features such as surface buildings would probably be removed as part of a decommissioning program.

There are two aspects of the information transfer problem worth examination: on-site information and off-site information. A site could be marked and clearly identified as a repository, with information ranging from the simplest "danger" warning to a complex description of the mine and its contents. Off-site information about the site could be recorded and stored in multiple sites anywhere in the world. Any plan to deliberately lose track of a backfilled mine would probably be frustrated by off-site information, while on-site information would not necessarily prevent deliberate intrusions. Storing the knowledge about a site in many places may greatly increase the likelihood of survival of 
that knowledge, but the society still would need the institution in order to make good use of the information.

In looking at historical precedents in long-survived information and at examples of lost information, it is important to appreciate the role of the relatively recent widespread use of writing and printing in man's history, and the geographic dispersal of that information. Today, disasters at a specific site would be much less likely than in earlier times to remove all traces of information about the site.

The following discussion, which includes historical examples of durable information, is intended to be illustrative rather than conclusive. It is principally intended to identify historical situations that provide useful background information.

There are numerous examples of highly complex abstract information that has been transmitted across a span of 1000 to 3000 years. Among the more significant are the large bodies of religious information that have been conveyed to the present by each of the world's major religions. Holy books, practices, and doctrines have been preserved in the face of wars, famine, plagues, and other natural calamities. What is perhaps most pertinent for the waste disposal issue is the fact that the information preserved by religious institutions not only is voluminous and highly complex, but also is set in abstractions. Complete technical information about nuclear waste sites is similarly voluminous, complex, and abstract.

Other examples of the extreme longevity of highly complex symbol systems can be seen in mathematics and engineering. The basic ideas of Euclidean geometry are thousands of years old. Basic engineering ideas involved in the construction of buildings, such as temples and other large structures, are likewise a few thousand years old. There is also a reasonably good history of the development of research science from the Middle Ages. Records of much early scientific work are surprisingly clear. Present-day researchers are privy to the recorded thoughts, insights, and analytic discussions of such thinkers as Leonardo da Vinci, Galileo, and Kepler.

The incentive to maintain records or bodies of information over long periods of time is an issue often raised. In the cases just 
cited, it can be argued that there was an economic incentive to preserve the information. This is particularly true in the engineering sciences and in mathematics, where practical applications are of obvious use to the societies that retained them. The fundamentals of chemistry, physics, and engineering will probably continue to be of utilitarian value to almost any technologically oriented society. Thus, there is some likelihood that societies far in the future will retain substantial bodies of technical knowledge that are generally known at present. A corpus of knowledge about nuclear chemistry would be a good candidate for survival on purely utilitarian grounds.

On the other hand, it should be noted that some of the highly technical information that has been developed in the past has not been passed on to present generations in any coherent form. Some ancient civilizations achieved phenomenal technological sophistication but left no records of how these accomplishments were actually carried out. Among these are the construction of the Egyptian pyramids. In Peru, there are numerous ruins in the highlands attesting to the fact that some civilizations during the pre-Inca period achieved a remarkable level of engineering skill in constructing fortress cities high in the Andean mountains. However, no written records are available describing how these feats were accomplished. Other examples of this extreme technological sophistication are, of course, to be found in the navigational skills of the Micronesians. Whether such losses of information could occur today or in the future is a matter for speculation.

In summary, there are historical examples suggesting that passing on detailed bodies of information of a highly technical nature is certainly not beyond man's capability. However, numerous counterexamples indicate that there are opportunities for such information to be lost or destroyed.

\section{SUMMARY AND CONCLUSIONS}

Human institutions may provide an increment of safety if monitoring, surveillance, and security operations are carried out during the first few centuries after a repository is closed. Human activities would provide a backup to the engineered system. This backup system 
would have the function of predicting the occurrence of natural hazards, preventing human intrusions, and responding to any anomalies that occurred at repository sites.

It is impossible to predict whether future societies would find it worthwhile to support institutions to carry out the functions noted above. It is also impossible to predict whether it is possible to convey information across millenia, or establish organizations that could last for such time periods. Discussion then has been in the vein of asking if there is any evidence to suggest that if organizational and institutional continuity were necessary, is there reason to believe that institutions established in the present might survive long enough to carry out their tasks?

The analysis of these issues is of necessity purely speculative, and based on historical examples that provide no firm basis for making predictions. However, there are numerous historical examples that suggest that complex information in abstract form can be maintained over thousands of years. Furthermore, many functional organizations have survived for a century or more while carrying out roughly the same tasks. A few have survived for a millenium. It would appear that the first century after closure of the repository would be the one where most of the human "hands-on" corrective actions might be needed. After 700 years, the radioactivity in the repository poses greatly reduced threat.

The principal conclusions of this analysis are:

- There are apparently no reasons in principle that would indicate that human institutions cannot survive for 100 to 200 years given reasonably stable political systems.

- Technical information can be maintained for a very long time if a culture remains literate, and the information has a continuing utilitarian value.

- Waste management systems adopted in the present time period should place minimal (preferably no) reliance on any human management after the repository is closed. 
1. G. Hardin, "Living with the Faustian Bargain," Bulletin of the Atomic Scientists, pp. 25-29, November 1976.

2. G. A. Cowan, "A Natural Fission Reactor," Scientific American, p. 36, July 1976 .

3. G. I. Rochlin, "Irreversibility and Multiplicity: Two Criteria for Disposal of Nuclear Wastes." Paper presented at the Conference on Public Policy Issues in Nuclear Waste Management, Chicago, IL, October 27-29, 1976.

4. A. Weinberg, "Social Institutions and Nuclear Energy," Science, 177:27-34, 1972 .

5. T. R. Lash and R. Cotton, Natural Resources Defense Council 1etter of November 15, 1976 to W. H. Pennington, US ERDA, commenting on suggested analyses in GEIS on nuclear waste management.

6. The role of institutions in long-term management has rarely been discussed. However, see Weinberg, n. 4.

7. T. LaPorte, "Public Acceptance of Technological Programs and the Reduction of Ambiguity: On Estimating the Socioeconomic Impact of Radioactive Waste Management," Institute for Governmental Studies, University of California, Berkeley, December 1976.

8. $10 \mathrm{CFR} 50 \mathrm{App}$. F. states the general proposition that waste management costs will be included as a portion of user charges. The mechanisms for accomplishing this have not yet been determined.

9. Task Group Report, Proposed Goals for Nuclear Waste Management. U.S. Nuclear Regulatory Commission, October 1976 (Draft).

10. S. M. Keeney, Jr., and Ford Foundation Nuclear Energy Policy Group, Nuclear Power, Issues and Choices. Ballinger Publishing Co., Chapters 2 and $8,1977$.

11. Office of Waste Isolation, Waste Isolation in Bedded Salt. Office of Waste Isolation, Dak Ridge, TN, 1976.

12. Handbook of Chemistry and Physics, 45th edition, Section B.

13. A. S. Kubo and D. A. Rose, "Disposal of Nuclear Wastes," Science, 182:1205-1211, 1973.

14. Handbook of Chemistry and Physics, 45th edition, Section B and item 15 .

15. W. Bishop and F. Miraglia, Jr., eds., Environmental Survey of the Reprocessing and Waste Management Portions of LWR Fuel Cycle. NUREG-0116-Supp. 1 to WASH-1248, U.S. Nuclear Regulatory Comm ission, October 1976. 
16. Bishop and Miraglia, n. 15, pp. 4-86.

17. See discussion in Bishop and Miraglia, n. 15, Sec. 4.4.2.1. Also see H. C. Claiborne and F. Gera, Potential Containment Failure Mechanisms and Their Consequences at Radioactive Waste Repository in Bedded Salt in New Mexico. ORNL-TM-4639, Oak Ridge National Laboratory, 1974.

18. Bishop and Miraglia, n. 15, pp. 4-88.

19. B. Cohen, "Environmental Hazards in Radioactive Waste Disposal," Physics Today, pp. 9-15, January 1976. Also Kubo and Rose, n. 13, and Bishop and Miraglia, n. 15.

20. A. Weinberg, "Social Institutions and Nuclear Energy," Science $177: 27-34,1972$.

21. La Porte, n. 7.

22. W. D. Rowe and W. D. Holcomb, "The Hidden Commitment of Nuclear Waste," Nuclear Technology, December 1974.

23. See n. 8 . 
CHAPTER V

SHORT-TERM INSTITUTIONAL ISSUES IN

IJUCLEAR WASTE MAINAGEMENT

\section{INTRODUCTION}

Much of the uncertainty surrounding the problem of nuclear wastes is over technical issues--the characteristics of the wastes, the relative effectiveness of different means of containment, the possible migration routes of radioactivity from the wastes to the biosphere, the health effects of different levels of radiation if released, and so forth. When issues like these have been resolved, a series of technical choices will be made, resulting in the best solution to waste management problems that scientists can devise.

But sound technical solutions are not enough to insure safety. These solutions are not self-implementing. Institutions--either those now existing or ones yet to be created--must carry out a waste management program. Setting up a waste management program therefore requires institutional choices as well as technical choices. Like technical choices, these institutional choices require analysis before decisions are made. In each case objectives (or criteria) need to be identified, alternative ways of attaining those objectives need to be discovered, and predictions must be made about how well different alternatives are likely to perform.

The discussion that follows presents some of the considerations in choosing among institutional alternatives for waste management. It suggests the range of alternatives and the range of problems that need consideration before sound institutional choices can be made. It will be clear to all readers that it is only the beginning of a thorough analysis of these issues.

Criteria for Choosing among Alternative Institutiona 1 Arrangements

The goal of any institutional system that is set up to manage radioactive waste is to protect the health and safety of the public. 
There are several possible arrangements of waste management institutions that might accomplish this goal. The principal criterion for measuring the adequacy of alternative institutional arrangements is:

- Performance. The system must carry out the technological tasks for which it is responsible.

Because it is not possible to know with certainty how institutions will perform, some additional criteria are useful:

- Accountability. It is important that a system be instituted to assure the accountability of the organizations to the public.

- Stability or durability. The organizations should be able to survive for the length of time necessary (which varies according to the task for which they are responsible).

- Adaptability. Since the organizations endure through several generations, they should be able to adapt to technological change, deal with unforeseen occurrences, and cope with changing political climates.

- Economic efficiency. An institutional system should provide a given level of performance at minimum cost ("cost-effectiveness"), and the costs of waste management should be borne by the users of the power that generated the waste.

Organizational Questions

When considering a waste management organization, one must consider the following questions, keeping the above criteria in mind:

1. Should management, regulation, and research and development be handled by one organization, or a number of separate organizations?

2. What should be the design of the management organization(s)?

a. Should there be one organization for all tasks (vertical integration) or several?

b. What kind of organization is best?

- Public, including federal agency; government corporation; government-owned, contractor-operated; contractor-owned, contractor-operated.

- Private. 
- Combination (e.g., private treatment and transportation, federal deep-burial repository).

c. How should the internal systems (i.e., personnel, finance, and management control) of the waste management organization(s) be designed?

d. What should be the design of the system for regulating waste management?

e. What should be the design of the R\&D organization?

Analysis stimulated by these questions will help decision makers choose a system of institutions that can best implement a waste management program.

There will still be a gap, however. Knowing the desired institutional arrangement is not the same as having the desired institutional arrangement. The status quo is something different. Consideration of the gap between what is and what should be is a necessary step in an institutional analysis. For management, for regulation, and for research and development, the questions are:

1. What organizations are now responsible for each type of waste and for each task?

2. How does the status quo system of organizations compare with the desired alternative on each of the criteria (performance, accountability, stability, adaptability, and efficiency)?

3. How likely is it that the necessary changes can be made to move from the status quo to the desired institutional arrangement?

These questions, and the alternative options available for each, form a framework for analysis of institutional issues in waste management. The discussion that follows expands on each question and on the alternatives available.

Dimensions of Waste Management

Waste management encompasses very different sorts of actions (as disparate as transportation, long-term monitoring, solidification of 
high-level liquid wastes, and regulation) affecting very different sorts of wastes (from high-bulk, low-level solid wastes to concentrated, highlevel liquid wastes). Some waste management actions are being taken now; different actions will be required in time spans one hundred or more years from now.

A11 these differences may affect the requirements for institutions to carry out the tasks of waste management. For example, the kind of organization needed to monitor a deep-burial site for several hundred years may be very different from the kind of organization needed to operate the treatment facility that solidifies high-level liquid waste. To clarify the situations in which answers to institutional questions may vary, the following list shows the dimensions of commercial nuclear waste management that may affect decisions on institutional issues. (1)

I. Technological dimensions

A. Different fuel cycle scenarios

1. No reprocessing; spent fuel rods are disposed of

2. Uranium recycle, plutonium storage

3. Uranium and plutonium recycle

B. Different types of wastes

1. Transuranic (TRU) waste

a. Spent fuel assemblies (if no reprocessing)

b. High-level waste (if reprocessing)

c. Other TRU waste (if reprocessing)

2. Effluents

3. Decommissioned facilities (may generate institutional problems quite different from other types of waste)

C. Different steps in waste management processes (these vary for each type of waste; some basic distinctions are listed below)

1. Interim storage

2. Treatment 
3. Transportation

4. Disposal or isolation

D. Different technologies available (these vary for each step for each type of waste)

II. Institutional dimensions

A. Different functions of a waste management system

1. Management of the wastes themselves (includes steps listed in I.C)

2. Regulation of the managers of the waste

3. Research and development

B. Time frames among which institutional requirements vary

1. Operational phase

2. Postclosure phase

C. Conditions of operation

1. Routine conditions

2. Response to nonroutine conditions

This chapter takes into account the different functions of a waste management system (II.A in the above outline) within the operational phase of the waste management system. It does not systematically discuss the institutional implications of any of the technological dimensions. Institutional requirements in the postclosure phase are discussed in an earlier chapter of this report.

\section{THE MANAGEMENT FUNCTION}

Vertical Integration of Waste Management

Should a single organization handle all nuclear wastes at all steps in the waste management system? One position, argued by $M$. Willrich, (2) is that due to the technological interdependence of different waste management steps, separate organizations are inefficient. For example, alternative methods for treating and packaging high-level liquid wastes may have substantially different impacts on tasks faced by three other 
parts of the waste management system--the disposal facility, the transportation industry, and the facilities treating the secondary waste streams.

The argument is that if each of these tasks is handled by a separate organization, each organization will minimize its own costs by attempting to pass problems on to others. The manager of the high-level liquid waste treatment facility will choose the treatment that is easiest and least costly for his facility to manage--even if that process results in large secondary waste streams, or in an output that is more difficult for the burial facility to handle. In contrast, if one organization is responsible for the entire process, it will choose the treatment that, in combination with its other choices, is optimal (i.e., that offers the best risk/cost trade-off).

An alternative argument holds that vertical integration may not solve the problem posed by technological interdependence. A single "Radioactive Waste Management Authority" would necessarily have different divisions--each responsible for a part of the problem or a step in the process. The decisions made within each division by division managers will be shaped by the incentives they face and by their view of the problem (which will inevitably narrow to include only their own responsibility--e.g., the manager of the calcination process is unlikely to concern himself deeply with the problems of deep salt burial). If the incentives are based on performance and cost criteria, the managers are likely to behave just as if they were in wholly separate organizations.

Some large organizations use sophisticated internal pricing systems to insure that one division's problems cannot be freely pushed off onto another division. In the above example, managers would charge for receiving waste. Thus, if one treatment generated a significantly smaller or less troublesome secondary waste stream, the manager of highlevel liquid waste would save money by choosing it. Similarly, the disposal facility would adjust its charges based on the costs of handling and burying the packaged high-level waste; again, the manager of highlevel liquid waste treatment would be able to integrate into his decisionmaking process the effects of his decision on the disposal facility. 
The internal pricing for waste management would be especially difficult to handle because of two special dimensions--uncertainty about the effects of technological alternatives on hazard, and the long time frame involved (each decision potentially affects hazard for years to come). Internal prices might reflect a great deal of error; thus, time might show that what was thought to be an optimal mix of treatment, packaging, transportation, and burial strategies was actually far from optimal.

If there were no "Radioactive Waste Management Authority"--but rather separate organizations handling treatment, packaging, transportation, and burial--the behavior of the managers of the separate organizations might be very similar to the behavior of division managers within a large organization. Managers of the separate organizations would face prices from the organizations with which they dealt. Those prices would presumably be set in much the same manner as are the internal prices in the case of the integrated organization.

It is not clear in either case whether the pricing system would guarantee that an optimal technical strategy would be chosen. But the point is that the choice of an integrated waste management organization does not in itself overcome the problem of technological interdependence. Organizational Options for Waste Management

Federal Agency

A federal agency (or other completely federal organization) has several characteristics pertinent to waste mangement:

1. Its employees ordinarily are members of the federal civil service. As a result, the agency management's influence over personnel actions (including the procedures for assigning job titles and pay grades, making promotions, awarding bonus or merit pay increases, giving warnings and suspensions, and firing employees) is limited by the rules and regulations of the Civil Service Commission.

The result of these restrictions on management is that the organization is less flexible than it would otherwise be. If 
the market for skilled employees changes, it cannot easily alter its salary levels to meet the competitive wage rates. If technological change demands a changing staffing pattern, the agency cannot easily make those changes.

2. Its funds are supplied by Congress in annual appropriations. Ordinarily there are restrictions preventing unused funds from being carried over from one fiscal year to the next. There are legal distinctions among types of funds--such as capital funds, operating funds, and stock (inventory) funds--that restrict the freedom of agency managers to use the resources of the agency in the way they see fit.

One result of the funding system is that agency managers must be responsive to Congress, especially to the chairmen and members of the House and Senate subcommittees that oversee their appropriations. This responsiveness is thought by some to be a defect, (3) but it may be just the opposite for waste management. The success of a waste management organization depends on having incentives built into the institutional arrangement to insure that the organization performs its task we11. The best incentive may be the regular public scrutiny of its operations, with the forum being the congressional appropriation process and the investigators being congressmen sensitive to public pressure, backed up by the investigative resources of the General Accounting Office.

3. A third important feature of a federal agency is the arrangement of its top management. In the simplest case, the agency has a single head, who reports directly to the President. (These agencies are called "independent" because they are outside the Cabinet departments. Examples are NASA and EPA.) Alternatively, some agencies are within cabinet departments; their heads report to the secretary of the department. In either case, the agency can be ignored by the President, and, as a result, will be free to choose its own course. Or, if a particular problem such as waste management requires additional attention, it is possible in either case for the President or the cabinet secretary to intervene. 
Government Corporation

A government corporation is a federally chartered organization with its own legal personality distinct from that of the federal government. (4) Advocates of the government corporation generaliy favor it on the grounds that it is "like a business":

Experience indicates that the corporate form of organization is peculiarly adapted to the administration of governmental programs which are predominantly of a commercial character-those which are revenue producing, are at least potentially self-sustaining, and involve a large number of business-type transactions with the public. In their business operations such programs require greater flexibility than the customary type of appropriation budget ordinarily permits. As a rule the usefulness of a corporation lies in its ability to deal with the public in the manner employed by private enterprise for similar work. (5)

The goverment corporation has several features relevant to waste management:

1. Since its employees are not part of the civil service, the managers of the corporation can design a personnel system suited to their own particular mission, and can retain control over al1 aspects of personnel management. This distinction may be important. It may be desirable to imbue the waste management employees with a sense of their own responsibility for a mission important to the nation and to the world; an independent personnel system could be used to help create and reinforce the necessary esprit de corps.

2. The customary financial system of a government corporation is like that of a business rather than a government agency.

The corporation derives its revenues chiefly from user charges for its services, rather than from congressional appropriation. It has the authority to borrow. It can make financial commitments without respect to fiscal year limitations. Its responsibilities to account for funds are prescribed by the Government Corporation Control Act, (7) and it is free from the more specific restrictions applied to government agencies by the Budget and Accounting Act. (8) 
Present policy for waste mangement ${ }^{(9)}$ holds that the costs of federal government waste management operations will be financed by producers of the waste. That policy dictates a financial system for the government organization like that commonly used by the government corporation. But the financial system need not dictate one organizational form:

There is nothing to prevent the Congress from conferring on a noncorporate agency some or all of the powers normally granted to a Government corporation, except separate corporate status, but the burden of proof shifts to those arguing for special treatment. (10)

3. The corporation will be more independent from executive and legislative control than would a federal agency. This independence may make it less accountable: "a public corporation that is insulated from immediate political pressure from the Executive Branch and Congress may also be unresponsive to public criticism."

Government-Owned, Contractor-Operated (GOCO) Organization

In many respects, the GOCO organizational arrangement is similar to the government corporation. The private contractor's flexibility with respect to personnel practices and financial systems is similar to the flexibility described for government corporations. It is not clear whether this arrangement provides for more or less accountability than does the government corporation. It might be thought that the private contractor would be more independent than would a government corporation. The existence of a contract, however, may provide a flexible tool that can be used by the monitoring agency to directly control the actions of the contractor. The contract can be used to provide the contractor with financial incentives to meet certain performance standards. If the monitoring federal agency is itself directly accountable to Congress, the agency may be responsive to congressional pressure for better contractor performance. In contrast, Congress may have only indirect control over a self-financed government corporation. 


\section{Contractor-Owned, Contractor-Operated (COCO) Organization}

The chief distinction between the COCO organization and a GOCO arrangement is in the financial exposure of the contractor. A contractor that owns a facility has much more capital committed to a project than one that merely operates a government-owned facility.

\section{Federally Regulated Private Enterprise}

Another possible institutional arrangement is for waste management to be performed by private firms, subject to federal regulation, monitoring, and enforcement (as is now the case for low-level waste management). Commercial nuclear power plants would contract with the waste management enterprises to dispose of their wastes. The waste management firms would be licensed and inspected by the federal government to insure management according to federal specifications. All commercial nuclear power plants would be required, as a condition of their operating license, to manage their waste according to federal regulations.

If the users of nuclear power are to bear the full costs of managing the associated wastes, this arrangement is a convenient way to let the market mechanism allocate those costs. In theory, the price charged for disposal of nuclear wastes would be constrained by the possibility of new firms entering into the waste disposal business themselves.

There is a fundamental choice to be made whether this industry should become a part of the government or a part of private enterprise. The arguments over public/private sector division of the economy are well known. The importance of waste managment in this issue can be determined by looking at the potential size of the waste management organization. One rough measure of the size is the costs of waste management. Rowe and Holcomb ${ }^{(12)}$ estimated that the annual costs of waste management in the year 2000 (the latest year for which they give an estimate) will be $\$ 1.7$ billion (in dollars inflated at 5\% annual1y). Their estimate is equivalent to $\$ 502$ million in 1975 dollars. A corporation with sales of $\$ 502$ million in 1975 would have ranked 344 th on the Fortune 500 index of industrial corporations. (13) This corporation's sales would have been about 0.0006 of the combined sales of the Fortune 500. Another gauge is its size relative to government: a federal waste 
management agency spending $\$ 502$ million in 1975 would have been smaller than any major federal agency. So the choice of public or private organizations for waste management will not appreciably affect the public/private division of the economy.

\section{THE REGULATORY FUNCTION}

Criteria for Sound Regulation

In addition to the criteria described at the beginning of this chapter, which apply to all aspects of the waste management system, there are two additional principles important in the regulatory system for waste management. First, there should be no conflicts of interest. The regulator must not have a stake in the success of the regulated. Second, redundancy is valuable for those regulatory tasks where the consequences of failure are high (safety review of facility design or inspection of monitoring programs are two such tasks).

Regulatory Tasks

The function of regulating the commercial nuclear waste management system includes several distinct tasks: standard setting, licensing, technical review, inspection, and enforcement.

\section{Standard Setting and Licensing}

These tasks are often done by the same organization. Sometimes, however, one agency (such as EPA) has the task of setting general rules for how tasks must be done (or what performance standards must be met), while another agency (such as NRC) has the task of applying those general standards to a specific case, and of granting a license to operate when proper conditions have been met.

\section{Technical Review}

A technical review is a check on the adequacy of the performance of either of the first two tasks. For the technical review to be effective, the organization responsible for it should be independent of the organization responsible for standard setting and licensing. The Advisory Committee for Reactor Safety performs this function in the field of nuclear power reactors. Congress mandated an independent technical review of the Lyons, Kansas, pilot burial facility (via the 
Pearson-Dole amendment to the 1972 appropriations for the Lyons project). Such a review is consistent with the two principles for waste management regulation described above. Technical reviews are designed to insure redundancy at key points, and should be independent in order to insure that each review does not become an automatic approval of a regulatory action.

\section{Inspection}

Inspection--the regular checking of the actual waste management operation to insure that it is being performed in the proper manner--is one of the most critical functions in the entire waste management system. If other parts of the system break down, a good inspection system will detect them. If the inspection system itself fails, no one will know if the waste management system is dangerously slipshod. The actual inspection task demands that people perform reliably on a continuing basis. The inspecting organization must therefore be designed in such a way to reward and encourage this performance.

A single inspection organization is not necessarily a guarantee of a good inspection system. Despite the fact that low-level waste burial sites were regulated by the Atomic Energy Commission (AEC) (in conjunction with state governments in most instances), and were inspected by AEC staff, an independent check by the General Accounting office found unsatisfactory practices at some sites. (14) Because of the importance of the inspection function, it may be wise to have two organizations perform inspections--each independent of the other.

\section{Enforcement}

The character of the enforcement function depends on whether private or public organizations are the target. In the case of private organizations, credible penalties, such as fines and license revocation, are available. Both of these penalties threaten the profit of a private licensee. The difficulty in using these penalties lies in defining the point at which fines or 1 icense revocations are justified. Most regulatory experiences and most regulatory weapons are negative in nature; they are designed to prohibit or limit certain kinds of conduct. When violations of regulations are acts of commission, they are relatively easy to detect and to use as the basis for penalties. With waste 
management, the problem, rather than being dangerous overt acts committed by the licensee, may be patterns of action somewhat less careful than necessary. The regulator will need to induce the licensee to act positively in a desired manner. In order to invoke penalites, the regulator will first have to carefully define the desired conduct, then establish that such conduct has not occurred. While it is possible to invoke such penalties, these regulatory actions will take longer to pursue and will be more difficult to pursue than prohibitory actions.

The public part of the waste management system presents special problems. The sanctions available to the regulator--fines, license revocations, and personal sanctions--cannot be expected to have the same effect on a public organization as on a private one.

Fines. It is not clear whether a federal regulator can fine another federal agency. If an agency can be fined, the fine might not come out of the agency's budget (since appropriations are often based on costs). Public agency managers, moreover, are rarely rewarded or penalized for the performance of their organizations. Therefore, fines, or the threat of fines, may not cause managers to change their actions.

Even if government organizations can be penalized, it is not clear that government officials are willing to use such a weapon in a conflict with another government organization. In the area of water pollution control, Ackerman (15) pointed out that there is a substantial economic argument for using fines to induce municipalities to cooperate. Even so, fines are rarely used: "The symbolic inappropriateness of resolving intragovernmental conflicts by the use of the criminal law, however, generally overshadows the 'economic incentive' argument in the eyes of the state officials."

License Revocations. Ordinarily, the threat of being put out of business ought to be sufficient to improve almost any organization's performance. But in the special case of an organization handling highlevel wastes, the regulator would need an alternative organization to handle the wastes. Unless such an alternative existed, any threat to revoke a license would not be credible.

Personal Sanctions. Some laws make individual officers of an organization responsible for certain standards of conduct, and they 
penalize violations directly by personal fines or jail sentences. These laws, however, are more common for private organizations than for public organizations. The use of criminal sanctions for public officials usually is restricted to instances in which officials use their office for personal gain. (Officials violating civil rights laws can be held personally liable, and gross negligence is usually grounds for penalties such as suspension or firing.)

None of these sanctions--fines, 1 icense revocations, or personal sanctions--seems likely to induce a recalcitrant public waste management organization to improve its standards of performance. The difficulty of defining desired conduct and proving that it has not occurred will, at a minimum, delay imposition of the sanction. Because these sanctions have clear defects, the regulatory agency "is much more apt to threaten to use its sanctions than actually invoke them." (16)

\section{Institutional Alternatives}

In the conventional approach to regulation, the tasks of standard setting, licensing, monitoring, and enforcement are often performed by a single agency. Today, NRC has the general responsibility for these tasks for nuclear matters within general standards set by EPA. While it would be possible to establish a different agency to regulate waste management, there appears to be no reason for doing so. However, some institutional questions about regulation remain.

As previously mentioned, it is worth considering whether there are some inspection tasks in waste management sufficiently important that at least two independent sets of monitors ought to perform them. Perhaps the General Accounting Office should be charged with periodically inspecting both the practices of the managers of nuclear wastes and the practices of NRC staff charged with monitoring performance of the waste managers.

Other unresolved regulatory issues include: first, the best division of responsibility between states and NRC in the regulation of low-level waste sites (where a recent GAO report cast doubt on the effectiveness of the current regulatory arrangement); second, the role of states in approving the siting of waste facilities (currently undefined); and third, the role of federal agencies other than NRC in 
regulating radioactive wastes--the extent of EPA authority, for example, is somewhat uncertain).

\section{THE RESEARCH AND DEVELOPMENT FUNCTION}

At present, the Department of Energy is responsible for government research and development in waste management. Funds for waste management research and development come from congressional appropriation. The actual research is ordinarily done by private organizations under contract to DOE.

THE STATUS QUO IN THE WASTE MANAGEMENT SYSTEM

The introduction to this paper pointed out that deciding what ought to be the appropriate institutional arrangement for waste management is not the same as having those arrangements in place. Indeed, there is an argument that what is is a better predictor of what will be than any alternative, no matter how attractive:

Major lines of organizational action are straight--i.e., behavior at one time, $t$, is marginally different from behavior at $t-1$. Simple-minded predictions work best: behavior at $\bar{t}+1$ will be marginally different from behavior at the present time. (17)

Al1ison's proposition is general: the present is the best predictor of the future, whether or not attempts are made to change the directions of organizations. But if no explicit choices are made about organizational responsibility for waste management, Allison's proposition has even more force: the future organization of waste management responsibilities will be only marginally different from the current arrangement.

Current Institutional Arrangements for Management

Since commercial waste management is not yet under way, there are some gaps in our ability to predict future organizational arrangements. But most responsibilities either have already been allocated or have been generally specified. 


\section{Low-Level TRU Waste}

Low-level TRU waste was handled like low-level non-TRU waste until 1974: it was buried in commercial shallow-land burial sites. At that time the AEC proposed to ban shallow-land TRU burial, but then withdrew the proposal. (18) Three states--South Carolina, New York, and Kentucky-now prohibit such burial, (19) and elsewhere the policy is unclear. The alternative to shallow-land burial is to dispose of low-level TRU waste like high-level waste--such a policy might be necessary due to the long life of the TRU components. If that policy is chosen, the organizational responsibilities for low-level TRU waste could parallel those for high-level waste, discussed below.

Spent Fuel Rods

At present, the utilities that operate reactors retain responsibility for spent fuel rods while those rods are stored in cooling ponds adjacent to the reactors. The spent fuel rods must then be packaged in casks and transported either to a reprocessing plant (if there is reprocessing) or to another interim storage facility or disposal site (if there is no reprocessing). When federal policy envisioned reprocessing, it was clear that commercial firms would be responsible for all steps in the handling of spent fuel rods up to and including reprocessing. In a fuel cycle without reprocessing, spent fuel rods must eventually be shipped to a repository. The federal government will have responsibility for operating that repository, but it has not yet been established when ownership of and responsibility for the rods will pass from the utility to the government.

\section{High-Level Liquid Waste}

High-level liquid waste would be generated at reprocessing plants, if U.S. policy were to permit fuel reprocessing. The private firm that ran the reprocessing plant would be responsible for the interim storage of high-level liquid wastes at the reprocessing plant site (in tanks) and for the solidification of the high-level liquid waste. The solidified high-level waste would be transported to a site for final disposal. According to testimony of Elliott Richardson (then chairman of the Energy Resources Councii) before the Joint Committee on Atomic 
Energy, a federal agency would probably take responsibility for the waste after it had been solidified at the reprocessing plant. (21) The federal agency would then be responsible for transportation to the disposal site, operation of the disposal site, and monitoring. According to Richardson, however, since the exact division of responsibility between the federal government and private sector had not yet been established in practice, it would be open to change. (22)

The phrase "federal agency" was used in the previous paragraph because there was in 1976 no official policy (either in law or regulation) as to what organization would have permanent responsibility for operating a disposal site. ERDA was then responsible for exploring potential sites and for constructing and operating demonstration waste respositories. However, responsibility is now clearly the Department of Energy's. The Department of Energy Organization Act (Pub. L. 95-91; 42 U.S.C. 7101) gave DOE the function of establishing temporary and permanent facilities and programs for the treatment, storage, management, and ultimate disposal of nuclear wastes.

Current Institutional Arrangements for Regulation

Agencies with regulatory responsibility for commercial nuclear wastes now include:

- EPA. The Environmental Protection Agency has responsibility for establishing generally applicable environmental radiation standards. (23)

- NRC. The Nuclear Regulatory Commission is responsible for implementation and enforcement of EPA's radiation standards. (24) INRC establishes regulations and policies for commercial waste management. It licenses waste management facilities, including ERDA's high-level waste storage facilities.

- States. In agreement states, state governments regulate low-level waste burial sites. In addition, states are able to regulate the transportation of nuclear materials in less than critical mass quantities solely within their own borders--these provisions could apply to the transportation of waste materials under some circumstances. (26) 
- DOE. Although DOE's ability to manage its own facilities might not be thought of as a regulatory responsibility, in practice it will be very much like a regulator. The actual operation of the facilities is apt to be done by private contractors, and DOE's setting of standards under which the contractors operate and its subsequent monitoring of the contractors are essentially regulatory functions.

- DOT. The Department of Transportation shares responsibility with NRC for the regulation of the transportation of radioactive materials. (27)

Much of the regulatory framework remains ambiguous. The boundaries between the authority of one agency and the authority of another are frequently unclear. Potential trouble spots include facility siting, transportation of waste, and regulation of low-level waste.

SUMMARY

This discussion has attempted to outline institutional issues in waste management rather than to resolve them. Accordingly, it is more appropriate to restate the problem here than to draw conclusions.

Resolution of waste management problems requires institutions to carry out solutions to technical problems. Institutions are needed to manage the waste, to regulate waste management, and to carry on research and development. Some of these institutions now exist; others remain to be created. The choices involved in creating both individual organizations, and an institutional system for waste management can have an important influence on the effectiveness of the waste management system. These choices should receive thorough analysis before they are made. 


\section{FOOTNOTES--CHAPTER V}

1. Note that the problem has already been divided once. This paper and the Generic Environmental Impact Statement deal only with commercial wastes and not with military wastes. The care of military wastes will also require institutions well-designed for the task.

2. M. Willrich et al., Radioactive Waste Management and Regulation. Energy Laboratory, Massachusetts Institute of Technology, Cambridge, MA, December 1976.

3. "An objection to government agency operations regarding radioactive waste management is their unbusinesslike character. The forces to which an agency such as ERDA is responsive are political, not economic." Willrich, n. 2, p. 5-19.

4. H. Seidman, Politics, Position, and Power: The Dynamics of Federal Organization. Oxford University Press, New York, NY, p. 229, 1970.

5. 1948 Budget Message of Harry Truman, House Document 19, 80th Congress, pp. M57-M62. Quoted in Seidman, n. 3, p. 235.

6. Seidman, n. 4, pp. 227-232.

7. 31 U.S.C. 841.

8. 31 U.S.C. 1.

9. 10 CFR 50, Appendix F.

10. Seidman, n. 4, p. 232 .

11. Willrich et al., n. 2, p. 5-21.

12. W. D. Rowe and W. F. Holcomb, "The Hidden Commitment of Nuclear Wastes," Nuclear Technology, December 1974. Reprinted in U.S. Congress, Joint Committee on Atomic Energy, Hearing on Storage and Disposal of Radioactive Waste, 94 th Congress, 1st session, p. 46, llovember 19, 1975.

13. "The Fortune Directory of the 500 Largest U.S. Industrial Corporations," Fortune, pp. 316-341, May 1976.

14. The Comptroller General of the United States, "Report to the Congress. Improvements Needed in the Land Disposal of Wastes--A Problem of Centuries," January 12, 1976. Included as Appendix 7 to U.S. Congress, Joint Committee on Atomic Energy, Nuclear Regulatory Commission Authorizing Legislation, Fiscal Year 1977 , Hearings Before the Subcommittee on Legislation of the Joint Committee on Atomic Energy. 94th Congress, 2nd session, 1976. 
15. B. A. Ackerman et a1., The Uncertain Search for Environmental Quality. The Free Press, New York, NY, p. 311, 1974.

16. Ibid.

17. G. T. Allison, Essence of Decision. Little, Brown, Boston, MA, p. 91,1971 .

18. 34 Federal Register 32421 .

19. W. 0. Doub, "Nuclear Waste Management: Problems of Organization in the Federa1/State System." Paper presented at the Conference on Public Policy Issues in Waste Management, Chicago, IL, October 28, 1976 , p. 18.

20. Testimony of E17iott Richardson in U.S. Congress, Joint Committee on Atomic Energy, Radioactive Waste Management, Hearings Before the Subcommittee on Environment and Safety of the joint Committee on Atomic Energy. 94th Congress, $2 \mathrm{~d}$ session, 1976, p. 24.

21. Ibid.

22. Ibid.

23. "Reorganization Plan No. 3 of 1970". In Code of Federal Regulations, Title 3--The President, 1966-1970 Compilation, Office of Federal Register, G.S.A., Washington, D.C., pp. 1068-1079, 1971. Also found in 71 Environmental Reporter, p. 211.

24. Nuclear Regulatory Commission, Opinion of the Commission in RuleMaking Hearings, Numerical Guides for Design Objectives and Limiting Conditions for Operation to Meet the Criterion "As Low as Practicable" for Radioactive Material in Light-Water-Cooled Nuclear Power Reactor Effluents. Docket No. RM-50-2, Apri1 30, 1975, at 5, note 3 .

25. 10 CFR 20.301 and 42 U.S.C. 5842.

26. Willrich et a1., n. 2, pp. 4-15.

27. Memorandum of Understanding between the United States Department of Transportation and the United States Atomic Energy Commission for Regulation of Safety in the Transportation of Radioactive Materials under the Jurisdiction of the Department of Transportation and the Atomic Energy Commission, March 22, 1973. 38 F.R. 8466; $1 \mathrm{CCH}$ Nuclear Regulation Reports 1009, 1975. 
CHAPTER VI

GENERAL ISSUES OF INTERGOVERIMMENTAL RELATIONS IN

IVUCLEAR WASTE DISPOSAL

\section{OVERVIEW}

A1though ERDA and INR have broad powers to engage in and to regulate nuclear waste disposal activities, state and local governments are insisting that they be included as full participants in the critical decisions relating to implementation of a nuclear waste disposal program. The discussion that follows sets forth a range of issues in which state and local governments have asserted policy positions that conflict with federal waste disposal plans or that have the effect of imposing burclens on nuclear activities beyond those imposed by the federal government. A successful wasie disposal program will require the federal government to be sensitive to state and local concerns while maintaining program efficiency and effectiveness.

\section{MAJOR ISSUE AREAS}

Cooperation between federal and state governments on waste management matters seems essential, yet many issues have not been resolved. The principal jurisdictional and political problems that currently characterize intergovernmental relationships in nuclear waste management are enumerated in the following discussion.

Extent of Federal Preemption of State Authority

A major legal issue to be resolved in nuclear waste management is the extent to which the federal government will preempt control or regulation of the siting, operation, and inspection of waste management facilities as well as regulate the transportation of nuclear waste materials. Although there is a consensus that federal statutes preempt state or local controls concerning radioactive emission standards (except state action under the Clean Air Act Amendments of 1977), the extent of federal preemption regarding other matters relating to nuclear waste management is unciear. To date, these issues have been resolved on a case-by-case basis by the courts. However, no clear set of 
precedents, which would cover the full range of waste management issues, has emerged.

Much of the political controversy between the states and the federal government centers on matters of how waste disposal sites will be chosen (technical criteria) and who will be involved in the decisions on where to finally locate the sites (policy criteria). Even if the courts determine that federal controls legally preempt certain state actions, political considerations seem to dictate that state participation in decision making is critical for a successful waste management program.

States are requesting advance notice of federal waste repository siting plans that may affect operations within their borders. The purpose of this advance notification is to allow state officials adequate opportunity to independently review proposals or plans, and to raise objections if appropriate. Increasing numbers of state officials have also requested or have attempted to exercise veto power over plans for siting or operation of waste disposal facilities within their borders. These expressions of interest by state government can be backed by legal and political actions that can impede or halt efforts by the federal government to site nuclear repositories or implement a national nuclear waste management program. The principal categories of potential state action are discussed below.

Land Use Management and Energy

Facility Siting Regulations

State or local governments have traditionally controlled land use planning and land use management. At the present time, 25 states have enacted legislation affecting power plant or energy facility siting. In addition, localities may become involved in energy facility siting through local planning and zoning arrangements. Just how these existing regulations and practices will affect selection of a site for disposal of nuclear wastes on nonfederal lands is unclear. Depending upon court interpretation of the relevant statutes, land use controls may permit the states to veto a federal site selection. 
Construction Standards

States and localities require numerous permits for construction of major facilities on nonfederal lands. These requirements include electrical standards, building codes, fire protection, road-building permits, water access, sewer requirements, and others. These requirements can influence construction costs for any major facility by causing costly delays, or extra capital outlays. As the doctrine of intergovernmental immunities severely restricts the applicability of state and local construction requirements where the activity is on federal lands, the greatest impact of local standards would be on off-site activities that affect the operation of a federal repository or on private commercial burial grounds for low-level wastes.

\section{Transportation Management}

States and localities often exercise controls over the transport of nuclear materials including shipnents of spent fuel or nuclear wastes moving through their jurisdictions. This can be accomplished by limiting speed, weight, or requiring specified notifications, routing, or escorts. Regulation of transportation may provide states and localities significant opportunities to influence nuclear waste disposal practices.

Environmental Standard Setting and Monitoring

Some states are requesting greater control over environmental protection and monitoring activities than is presently permitted or required by IVRC. Also, it is not fully clear what the ultimate impact of 1977 amendments to the Clean Air Act will be on state powers to regulate radioactive waste disposal sites, and transportation of radioactive materials. Some states have shown particular interest in effluent monitoring, pollution control, and gaining authority to shut down facilities operating within the state that are not in compliance with state standards. Such concerns indicate that some states wish to become actively involved in rule making and standard setting germane to environmental protection.

\section{Emergency Preparedness Planning}

States and localities have in the past been primarily responsible for developing emergency preparedness plans to implement in the event of 
a transportation accident or an accident at a fixed nuclear facility. It is likely, given state interests in nuclear issues, that emergency preparedness planning will become an even more salient issue for state and local governments.

\section{FEDERAL PREEMPTION POWER AND STATE ACTIVITIES}

In recent years, states have adopted a variety of controls over various aspects of nuclear power operations conducted within their borders. Because federal regulation of nuclear activities is comprehensive and detailed, such state actions raise preemption issues that present difficult questions of statutory interpretation.

There are two contending schools of thought on state controls over nuclear activities. One view maintains that the federal regulatory framework is so pervasive that ultimately state attempts to regulate nuclear activities are preempted under the Commerce clause and the Supremacy Clause of the U.S. Constitution. $(1,2,3)$ The converse view is that federal regulation is not so pervasive and that federal preemption does not extend to regulations that have purposes other than control of radiation hazards, even though such requirements might have an incidental effect on federally licensed activities. While regulation of some activities may be preempted, states have appropriate and valid jurisdiction over many other aspects of the nuclear program. (4)

In general terns, the preemption doctrine means that, where an activity is subject to regulation under both federal and state law, the federal law will prevail in cases where (a) compliance with both the state and federal laws is impossible or (b) when under the circumstances the state's law stands as an obstacle to the accomplishment or execution of the full purposes and objectives of the Congress. Since the Congress has made no express statement of intent to preempt state law concerning nuclear waste disposal, the question of how the general principles above apply to issues in waste management is open to strenuous debate.

The courts have held invalid on preemption grounds state regulations aimed at regulating radiological aspects of the nuclear fuel cycle because of the comprehensive regulatory scheme created by the Atomic 
Energy Act. (5) Section 274 of this act does provide for a limited state role. Murphy and LaPierre interpret this section as allowing state regulation of radiation hazards only under an agreement with the AEC (formerly ERDA, now the Department of Energy). (6) Furthermore, Section 274(c) specifically excludes'a number of areas from the scope of any agreement between the federal agency and a state. These excluded areas are:

1. Construction and operation of production or utilization 'facilities.

2. Export or import of source, by-product, or special nuclear materials, or of any production or utilization facility.

3. Radioactive waste disposal to the extent specified in AEC regulations or orders. (7)

The first judicial decision dealing with the question of preemption involving nuclear waste management was Boswell v. City of Long Beach. The city of Long Beach attempted to block the plaintiff's radioactive waste disposal activities. The court held that the city had no power to interfere, since the plaintiff's operations were conducted under AEC supervision. The court added that, since the wastes must be transported by interstate commerce for long distances and through many communities, disposal of radioactive wastes is not simply a local concern.

The leading case on the question of federal preemption of a state's authority to regulate radioactive waste releases into navigable waters is the 1971 case of Northern States Power Co. v. Minnesota. (9) In this case, a privately owned electric power company constructed a nuclearfueled electric generating plant under the authority of a provisional permit issued by the AEC. The company subsequently sought a waste disposal permit from the state pollution control agency, as required by state law for the discharge of pollutants. The waste disposal permit was issued, but was subject to conditions regulating the radioactivity level of effluents from the plant. The restrictions covered the same areas as the AEC regulations imposed under federal law, but were considerably more stringent. The company challenged the constitutionality of the state controls, charging that they were precluded under the 
Atomic Energy Act of 1954. The court held that for the purposes of protection against radiation hazards, the federal government has exclusive authority to regulate the construction and operation of nuclear power plants, and this necessarily includes the authority to regulate levels of radioactive effluents discharged from the plant. (10) An important consideration for the court was Northern State's direct engagement in interstate commerce.

As discussed below, with respect to radioactive emissions into the air, however, the legislative history of the Clean Air Act Amendments indicates that the holding in Northern States is not to be followed.

While there is general agreement that regulation of radioactive discharges is an area specifically preempted by the federal government (except radioactive discharges into the air), the situation is not at all clear, however, in other substantive areas of state regulation that do not directly deal with radioactive discharges, but may significantly affect the operation of a nuclear facility. The Supreme Court's orientation has been characterized as follows:

The Supreme Court, however, has not developed a uniform approach to preemption; its decisions in this area take on an ad hoc unprincipled quality seemingly bereft of any consistent doctrinal basis. (11)

Hendrickson and Schilling made the following observation when examining federal and state jurisdictional issues in the control of hazardous substances:

While preemption has been found in widely varying circumstances, the present disposition of the U.S. Supreme court appears to be based on a "conviction that the proper approach is to reconcile 'the operation of both statutory schemes with one another rather than holding one completely ousted. " (12) In any event, the finding of preemption will rise from consideration of the particular issue at hand; any conclusions from the discussion are merely predictions of what the courts may hold if a case arises. (13)

Thus, it would appear that, barring congressional action, the states have several opportunities to influence projects carried out in nuclear waste management.

In addition, Willrich noted that the operational reality of federal relations requires recognition of the political and economic implications 
of a federal-state confrontation. Whether or not state regulation would be eventually declared federally preempted, the governor, legislature, or people of a state can in many ways resist activity within the state's borders that is authorized or directed by the federal government. (14)

In this regard, states have at their disposal several legal means to apply pressure on any federal project that does not meet with state approval. A number of the more salient areas will be discussed in the balance of this paper.

\section{STATE PARTICIPATION IN DECISION MAKING}

Regardless of what arguments are offered about the legality of state control over various nuclear activities, there is no question that officials in states and localities being considered as potential locations for a waste repository want to be meaningfully involved in the decision-making process at an early stage. (15) As noted earlier, the earliest point at which significant involvement can occur is in the definition of candidate sites for waste repositories. Thus, a good deal of the public controversy centers on the definition of appropriate sites.

Variations have been expressed as to the degree to which state officials wish to participate in the decision-making process with regard to site selection. Participation can range from the position that the states have the power to veto any plans to dispose of nuclear waste within their jurisdiction, to a passive review of waste disposal project plans. Not all state officials have demanded veto power over site selection. However, officials in all of the states considered candidates for a repository site have indicated that at a minimum, they want to be apprised of developments on a timely and continuing basis. (16)

Among the more formidable positions taken on this matter are two "nuclear states rights" bi11s, introduced in January 1977 by Rep. M. K. Uda11 (D. Arizona), that would allow states to stipulate conditions for the construction of nuclear facilities and to disapprove construction of a proposed installation before NRC approval took effect. (17) Either measure would serve to give states the legal authority to approve or disapprove of nuclear facilities to be sited within their borders. 
Involvement of state officials early in the process of site selection and evaluation may take several forms. One theme that has been raised is the provision of information to state officials at a point in the decision-making process when they may exert meaningful input. This would help insure that state officials have adequate time and resources to make responsible decisions.

To this end, in 1976 ERDA notified the governors of states that the federal Office of Waste Isolation may initiate geological exploratory operations within their borders in the near future. The Office of Waste Isolation took pains to notify state officials at the earliest stages of the possiblity of conducting geotechnical explorations in specific areas.

Many states have established procedures for review and regulation of energy facilities sited within their jurisdiction. As of August 1977,25 states have enacted legislation that provides for state review and/or approval of new electric power plant facilities. (19) Some of these state laws provide only for state approval of new generating facilities (e.g., New Hampshire's Electric Power Plant Siting Act). Others, however, provide for state approval of all energy-related facilities, including refineries and pipelines as well as power plants (e.g., Washington's Energy Facility Siting Law). It appears likely that plans for waste repositories will be examined by the state agencies currently empowered to review proposals for other energy facilities. It is very likely that some state agencies will review repository proposals, even in those states where a more narrow site-review mandate presently exists.

\section{CONSTRUCTION STANDARDS}

State approvals are required for a wide variety of nonnuclear components necessary in the construction of any nuclear facility. The specific approvals needed vary somewhat among the states. An illustrative list of state approvals needed for a power plant in Oregon includes: (20)

1. Plans, specifications, and construction methods for dams.

2. Permit for railroad spur (to cross a highway). 
3. Design of intake/pumping facility (from the standpoint of fish resource protection).

4. Effects of waste discharge during construction.

5. Design and construction of sewage stabilization pond.

6. Design of sanitary water system.

7. Pressure vessel and piping code inspection procedure in compliance with state boiler and pressure vessel law.

8. State fire marshall inspection of construction drawings.

It is unlikely that many state approvals would be imposed on a federal waste management facility on federal lands. There is a strong possibility that these types of approval would be needed to develop commercial burial grounds. In the latter case, states would wield considerable power over whether a given site might become operational, or be closed down, by denying or revoking some necessary permits.

\section{RELATIONSHIP OF LAND USE MANNAGEMENT}

ISSUES TO ALTERNATIVES FOR NUCLEAR
WASTE MANAGEMENT

The 10th amendment of the U.S. Constitution reserves for the states a11 powers not explicitly delegated to the federal government. Among these residual powers is the regulation of land use for land lying within the states' boundaries. Generally, states, as a matter of practice, have turned over land use controls to local governments.

Recently conflicts have arisen in some states over the acquisition (or attempted acquisition) of private land for the possible purpose of constructing nuclear waste repositories. These conflicts illustrate the problem of defining the role that state and local land use regulations have in limiting or restricting acquisition of sites for waste repositories.

In some instances, federal and state agencies have developed joint programs for siting power plants. NRC and New York's ERDA have also evolved policies for conducting joint reviews of power plant siting plans. ${ }^{(21,22)}$ These examples of state and federal cooperation in power plant siting stand in sharp contrast to the situation that prevails in designating potential waste repository sites. In this regard, Wi17iam 0. 
Doub noted that in waste management matters the federal-state interface is not functioning well at all. In particular, there has not yet been developed a set of systematic or uniform criteria that either the states or the federal government may use in the selection of waste repository sites. Furthermore, there are no standardized procedures for conducting reviews of potential sites. (23)

Significant ambiguities exist over the way in which land use regulations and controls may affect the designation and ultimate selection of waste repository sites. If Congress expressly preempts the field of management of nuclear wastes, then acquiring sites for federal repositories would become more straightforward than it now seems to be.

In the absence of an expressed declaration of preemption by the Congress, siting matters will probably be subject to extensive 1 itigation and political conflicts. The Supreme Court has not yet squarely considered the issue of state or local land use controls with respect to federally licensed atomic energy facilities. Furthermore, highly sophisticated legal scholars have drawn totally different inferences about the likely course of Supreme Court decisions in this area.

When considering the issue of state and local control over identifying and ultimately selecting sites for nuclear waste repositories, it should be noted that there are a number of wholly legitimate procedures that can be utilized by states and localities to delay implementation of federal plans for a repository. (24) In every state there are permits required--for everything from water discharge to road construction--that contractors must obtain from appropriate state agencies before they can proceed with construction. States and localities can cause delays in issuing these permits and can bring political pressure on the federal agencies charged with the responsibility of building waste repositories.

\section{TRANSPORTATION OF RADIOACTIVE WASTE MATERIALS}

The U.S. Department of Transportation and the Nuclear Regulatory Commission regulate the transportation of radioactive material. To minimize risks to the public and transportation workers, their regulations establish shipping container requirements, allowable radiation 
doses, and handling procedures. While DOT and iNRC dominate the regulation of radioactive material transportation, state governments also exercise control over these shipments. Most states have promulgated requirements to complement the federal regulations. State transportation agencies have regulated truck transport historically by closing certain routes to hazardous cargo and by defining maxiumum gross vehicle weights, vehicular dimensions (both height and girth), and speed limits. Such limitations generally apply to radioactive cargo as well as to other hazardous freight. Additionally, about one-half of the states have enacted the U.S. Department of Transportation Hazardous Materials Regulations to apply to intrastate shipments. (25)

Generally, the states that have adopted legislation on the subject of transportation of radioactive materials continue to stress in their regulations compatibility and compliance with federal regulatory requirements, emphasizing that state provisions are not to be interpreted as replacing federal regulations on the subject. In fact, federal regulations themselves provide for a state role.

Under the federal statutory scheme, it appears that there may be at least four ways in which a state can validly regulate transportation of nuclear material. These are:

First, under Section 112 of the Hazardous Materials Transportation Act, state regulation of the transportation of hazardous materials may be upheld if (a) such state regulation is consistent with the federal scheme of regulation; or (b) if such state regulations are inconsistent with federal regulations, they may still be imposed if the Secretary of Transportation or his delegate determines that such a state reqirement (i) affords an equal or greater level of protection to the public than under federal statutes and regulations, and (ii) does not unreasonably burden commerce. An administrative procedure is available for making these determinations. (26)

Second, under Section 274 of the Atomic Energy Act of 1954, the Nuclear Regulatory Commission may relinquish to states individualiy, by agreement, certain aspects of the commission's otherwise exclusive responsibility for reguiating radiological hazards arising from the use or transportation of radioactive materials. 
Third, Section 274 of the Atomic Energy Act also confirms that federal preemption does not extend to state or local regulations that have purposes other than the control of radiation hazards even if such requirements may have an incidental impact upon the use of nuclear materials licensed by the Nuclear Regulatory Commission.

Fourth, in some cases, a state may be free to regulate the intrastate aspects of certain nuclear shipments.

However, there are some recent examples of state actions that seek to regulate independently the shipment of nuclear materials, including wastes. For example, Connecticut, New Mexico, Oregon, and Vermont have adopted requirements providing for routing controls or prohibitions on the transport of radioactive materials. The connecticut legislation, for example, while careful not to conflict with federal regulations in the field of packaging and shipment, prohibits shipment of large quantities of radioactive materials as defined in 10 CFR 71 and any quantity of radioactive waste that is being shipped from or through the state to a waste disposal site without a permit issued by the State Commissioner of Transportation. (27) The Commissioner may require changes in dates, routes, time of shipment, or escorts if he deems it necessary to protect the public. Section 1D of the act exempts military or national security shipments but does cover other shipments by the United States. Litigation over time can clarify and delineate the validity of these types of state actions.

Another set of issues that have not yet been resolved centers on the degree to which states and localities can require shipment of nuclear materials by circuitous or rural routings, bar shipments through certain areas, or place limitations on the hours of movement. In an initial administrative decision, the Department of Transportation has recently determined that a New York City prohibition on the transportation of radioactive materials through the city is not inconsistent with the Federal Hazardous Materials Transportation Act.

The great majority of radioactive materials shipped today move in routine commercial transport equipment. The safety factor in transportation, vis-à-vis roliting, was characterized in an AEC publication in 1972 as follows: "Safety in transportation does not depend on special 
routings, although special routings are used at some bridges and tunnels to avoid possible interference with the flow of traffic should an accident occur."

In summary, a number of states have adopted transportation regulations that are in addition to, or perhaps inconsistent with, federal controls. The validity of state regulations may be challenged in court and some may be found to be preempted by federal control. However, such state control can have an important impact on waste disposal activities.

STATE PARTICIPATION IN STANDARD SETTING AIND ENVIRONMENTAL MONITORING

Based on experience gained with nuclear power plants during the past 20 years, a number of officials in different states are making a case for increasing state participation in standard setting and environmental monitoring. Such participation provides firsthand information to state officials and, in some instances, provides an independent assessment of federal inspection or monitoring work. Such a view is expressed in the following statement concerning state participation in nuclear power plant inspections:

. . the states do not want to be in a position where they know only as much as the [federal] inspector decides to tell them. The states want to be able to assure the public regarding the quality of construction. The states are the ones who can most effectively refute charges such as that the government glosses over sloppy workmanship or that there is an unwholesome alliance between the Nuclear Regulatory Commission and the utilities. . . (29)

States have expressed interest in being actively involved in radiological and water quality monitoring. In the absence of any sites designated as waste repositories, however, states have not vigorously pressed this issue. Once specific sites are designated, pressures for state involvement in monitoring and standard setting can be anticipated.

Section 122 of the Clean Air Act Amendments of $1977^{(30)}$ may sharply change preexisting regulatory authority concerning radioactive emissions into the air. That section provides that emissions from radioactive substances, including source, by-product, and special nuclear materials, are to be regulated under the Clean Air Act. By August 1979, the 
Administrator of the EPA must determine if radioactive emissions contribute to air poliution in a way which may endanger public health. If an affirmative determination is made, the EPA must regulate the pollutant. Under the Act, states may establish emission standards that are more stringent than EPA standards. The nature and implication of this state authority will now be explored further.

Prior to the 1977 Clean Air Act Amendments, traditional interpretations of the Atomic Energy Act of 1954 had consistentiy held that the Act preempts any state authority from regulating radioactive emissions for the purpose of protection from radiation hazards. (31) The exclusive regulatory authority to estabiish standards for radiation hazards was held to be the NRC.

However, the 1977 Clean Air Act Amendments make clear that states are no longer precluded from establishing and enforcing standards to regulate radioactive emissions into the air. Accordingly, under the 1977 Amendments, there are at least four approaches that a state may take in the regulation of radioactive emissions into the air:

1. A state may adopt standards before any action is taken by the EPA. The intent of Section 122 was to remove 1 imitations on the states in the regulation of radioactive emissions into the air.

2. A state may wait for the promulgation by the EPA of standards and then adopt those standards as its own. The conference report on the 1977 Amendments indicates that the EPA may choose to promulgate identical standards to those previousiy established by the NRC. However, the EPA may do so only to the extent that it finds such standards adequate to fulfili the requirements of the Clean Air Act. The 1977 Amendments also permit the NRC to disapprove any EPA, state, or Tocal standard promulgated under the Clean Air Act if the NRC finds that the application of such a standard to a source or facility within its jurisdiction would endanger public health or safety. The President may overturn such an NRC disapproval within ninety days, upon appeal by the agency that promulgated the disapproved standard. Thus, if the EPA adopts IRRC 
requirements, the states may in turn promulgate these standards. This is the regulatory approach primarily contemplated by the Clean Air Act and which is most often used by the states.

3. A state may wait for the promulgation of EPA standards and then adopt standards more strict than EPA's. This approach is expressly permitted by the Clean Air Act and may be pursued by a state if it determines that the EPA has not adequately addressed state interests in developing the federal standards.

4. A state may decide not to adopt any standards whatsoever and not to enforce any standards promulgated by the EPA. In this case, the EPA, or by cooperative agreement, the NRC, would directly enforce the Clean Air Act emission requirements.

\section{EMERGENCY PREPAREDINESS AND ACCIDENT ISSUES}

A number of highly charged public issues have arisen with regard to potential problems posed by nuclear accidents. Accidents involving nuclear waste materials are often considered as a subset in the more general discussion.

State and local governments have the responsibility of developing emergency preparedness plans for dealing with a variety of accidents or disasters. Nuclear accidents, either at fixed sites or on transportation routes, are among the potential problems that should be addressed in emergency plans.

In the case of nuclear power plants, the operator of the plant, as a condition of licensing, must develop plans to deal with emergencies. In addition, the Nuclear Regulatory Commission urges states and localities to prepare emergency response plans and provides guidance as to the adequacy of such plans. NRC has no statutory authority to mandate such planning; however, it has prepared a document for state and local officials to use in developing or evaluating the adequacy of their own emergency plans. (32) It may be presumed that emergency plans dealing with accidents at waste repositories will bear a strong resemblance to plans prepared for accidents at other types of fixed nuclear sites. (33) 
If a radiological incident should occur at a nuclear facility or during the shipment of nuclear materials (including wastes), present arrangements call for the Interagency Radiological Assistance Plan (IRAP) to go into effect. (34) IRAP is intended to provide a coordinating structure whereby federal, state, and local emergency teams monitor and control activities at an accident site.

DOE is the agency responsible for directing the overall administration, implementation, and application of the provisions of IRAP among the participating federal agencies. It is expected to carry out its responsibility through a national coordinating office at DOE headquarters and through regional coordinating offices located at eight field offices.

In the event an accident occurs involving commercial nuclear wastes, any damages that might accrue to third parties would be subject to liability claims. Total liability for any nuclear incident is currently limited to $\$ 560$ million by the Price-Anderson Act (as more reactors are licensed, this liability limit will gradually increase). Much controversy surrounds the Price-Anderson Act and the limitation of aggregate liability of $\$ 560$ million for any single nuclear incident. Some critics maintain that any limitation of liability improperly relieves companies in the nuclear business from being fully responsible for their actions. In one instance, a federal district court decision has upheld this contention. (35) Whether the Supreme Court will uphold this decision remains to be seen. It also remains to be seen what impact liability issues will have on the disposal of commercial nuclear wastes in either federal repositories or private burial grounds.

Other issues pertaining to liability in the event of transportation accidents have yet to be resolved. Several railroads are petitioning in proceedings before the Interstate Commerce Commission to cease acting as common carriers of spent fuel and radioactive wastes. If these railroads prevail, it would permit them to insist upon individually negotiated contracts that could contain comprehensive hold-harmless agreements in favor of the carrier, covering, among other things, any damage to railroad property and liability to third parties regardless of the shipper's fault. ${ }^{(36)}$ The ICC has generally ruled against the railroads in these proceedings. 
LOCAL GOVERNMENT ACTIVITIES RELATED

TO WASTE MANAGEMENT OPERATIONS

Local governments have traditionaliy exercised zoning and land use planning powers to regulate activities that occur within their jurisdictions. Although zoning and land use planning controls may not directly impinge upon federal repositories, it is clear that in a number of instances, localities may utilize such powers to hinder implementation of plans to the point where implementation may no longer be feasible.

Local communities become involved in the evaluation and management of socioeconomic impacts associated with constructing and operating large industrial facilities within their jurisdictions. Clearly, the construction and operation of a waste management facility would involve substantial social and economic impacts on the small communities that might serve as host sites.

Local communities are also involved in emergency preparedness planning, either for transportation accidents or for industrial accidents at waste management complexes. The local police force or fire department is often called to the scene first in any accident situation. As such, local governments have a distinct continuing concern about emergency preparedness actions.

\section{SUMMARY}

Many critical issues involving intergovernmental relations in nuclear waste management remain to be worked out. The discussion above has highlighted some of the more significant problem areas.

The resolution of some issues has begun by statutory amendment (i.e., the Clean Air Act Amendments of 1977) or by taking the matter into the courts (e.g., the liability limitation provided by the PriceAnderson Act). The Nuclear Regulatory Commission has also completed a series of studies aimed at improving regulatory effectiveness in federal/ state siting actions. (37) However, many of the most critical policy issues have not been resolved. In the absence of a clear statement of federal intent regarding preemption, siting, licensing, and operating, a nuclear waste repository will probably be accomplished only after protracted bargaining, negotiation, and possibly litigation. 
FOOTNOTES--CHAPTER VI

1. U.S. Const., Art. I, Sec. 8, C1. 3.

2. U.S. Const., Art. VI, Cl. 2.

3. Murphy and LaPierre, "Nuclear 'Moratorium' Legislation in the States and the Supremacy Clause: A Case of Express Preemption." Columbia Law Review 76:392, 1976.

4. Hon. M. O'Callaghan, "State Input to the Decision-Making Process." In: States' Role in Radioactive Material Management, National Conference of State Legislatures, Committee on Science and Technology, Council of State Governments, Lexington, KY, 1974.

5. See, e.g., Northern States Power Co. v. Minnesota, 447 F.2d 1143 (8th Cir., 1971), aff'd mem., 405 U.S. 1035 (1972).

6. Atomic Energy Act of 1954, Sec. 274, 42 U.S.C. 2021 (1970).

7. 42 U.S.C. 2021 (c) (1)-(4)(1970).

8. Boswell v. City of Long Beach (Cal. Sup. Ct., 1960), 1 Atomic Energy L.R., Sec. 4045.

9. Northern States Power Co. V. Minnesota, 447 F.2d 1143 (8th Cir., 1971), aff'd mem., 405 U.S. 1035 (1972).

10. Id. at 1154 .

11. "The Preemption Doctrine: Shifting Perspectives on Federalism and Burger Court." Columbia Law Review 75:623, 1975.

12. Merri11, Lynch, Pierce, Fenner and Smith, Inc. v. Ware, 414 U.S. 117,27 (1973), quoting Silver v. New York Stock Exchange, 373 U.S. $341,357(1963)$.

13. P. Hendrickson and A. H. Schilling, Evaluation of Hazardous Material Transportation by Rail in Illinois. Battelle Pacific Northwest Laboratories, Richland, WA, March 1977.

14. M. Willrich et al., Radioactive Waste Management and Regulation. Report to US ERDA from the M.I.T. Energy Laboratory, September 1, 1976 (Draft).

15. W. E. Davis, "Idaho Establishes a Study Commission on Commercial Radioactive Wastes." In: State's Role in Radioactive Material Management, n. 4.

16. Detroit Free Press, July 18, 1976, Sec. A at 3, Col. 1, Sec. A at 7, Col. 1 .

17. Public Power Weekly Newsletter, p. 5, March 21, 1977. 
18. Hon. M. O'Callaghan, "State Input into the Decision-Making Process." In: State's Role in Radioactive Material Management, n. 4.

19. States with siting laws for power plants are: Arizona, Arkansas, Cal ifornia, Connecticut, Florida, Iowa, Kansas, Kentucky, Maryland, Massachusetts, Minnesota, Montana, Nevada, New Hampshire, New Jersey, New Mexico, New York, irorth Dakota, Ohio, Oregon, South Carolina, Vermont, Washington, Wisconsin, and Wyoming.

20. W. K. Woods, "State Regulation of Sited Nuclear Power Plants." Paper presented at a meeting of the Atomic Industrial Forum. Nuclear Dialog for State Regulators, Detroit, MI, October 1976.

21. Ibid.

22. D. Rapp, "The Role of State Decisions in Licensing Reviews." Paper presented at the Atomic Industrial Forum Workshop on Reactor Licensing and Safety, Washington, DC, June 1976.

23. W. 0. Doub, "Problems of Organizational Structure in the Federal/ State System." Paper presented at the Conference on Public Policy Issues in Nuclear Waste Management, Chicago, IL, October 27-29, 1976.

24. M. J. Curry et a1., State and Local Planning Procedures Dealing with Social and Economic Impacts from Nuclear Power Plants. Battelle Human Affairs Research Center, Seattle, WA, 1977.

25. "An Overview of Transportation in the Nuclear Fuel Cycle," Workshop on Nuclear Materials Transportation, 1976-2000. Battel 1e Northwest, Seattle, WA, March 30-31, 1976. Appendix B, "Government Regulations Pertaining to the Transportation of Radioactive Materials," at 10 .

26. 41 Fed. Reg. 38167 (1976).

27. 3 Conn. Leg. Serv. (1976), 76-321.

28. WASH-1238, "Environmental Survey of Transportation of Radioactive Materials to and from Nuclear Power Plants." United States Atomic Energy Commission Directorate of Regulatory Standards, at 4 (1972).

29. Woods, n. 21 .

30. 42 U.S.C. 7422 .

31. Northern States Power v. Minnesota, 447 F. 2d 1143 (8th Cir. Ct., 1971) aff'd 405 U.S. 1035 (1972); Train v. COPIRG, 426 U.S. 1 (1975).

32. U.S. Nuclear Regulatory Commission, Guide and Checklist for Development and Evaluation of State and Local Government and Radiological Emergency Response Plans in Support of Fixed Nuclear Facilities. NUREG-75/111. Washington, D.C., 1975. 
33. R. W. DeFayette, "Trends in Emergency and Evacuation Plans." US Nuclear Regulatory Corimission. Washington, D.C., October 1976.

34. US ERDA, ERDA Radiological Assistance Plan, 1975.

35. Carolina Environmental Study Group v. AEC, 2 Nuclear Regulation Reporter 16, 309 (W.D. N.C. March 31, 1977).

36. W. England, "Transportation of Nuclear Fuel and Other Radioactive Materials." Paper presented at ALI-ABA Conference on Atomic Energy Licensing and Regulation, San Francisco, CA, October 1976.

37. U.S. Nuclear Regulatory Commission, Improving Regulatory Effectiveness in Federal/State Siting Actions. (10 Reports) NUREG-0195 through NUREG-0204, USNRC, Washington, D.C., March 1977. 
No. of

Copies

\section{UNITED STATES}

\section{A. A. Churm}

DOE Chicago Patent Group

9800 South Cass Avenue

Argonne, IL 60439

Deputy Director for Fuels and Materials

NRC Directorate of Licensing for Fuels and Materials

Silver Springs, MD 20910

W. P. Bishop

Assistant Director for Radioactive

Waste Management Branch

NRC Division of Materials and

Fuel Cycle Facility Licensing

Washington, DC 20555

W. G. Belter

DOE Division of Biomedical and

Environmental Research

Earth Sciences Branch

Washington, DC 20545

W. A. Brobst

DOE Division of Environmental

Control Technology

Washington, DC 20545

W. E. Mott

DOE Division of Environmenta1

Control Technology

Washington, DC 20545

G. W. Cunningham

DOE, Administrator for Nuclear Energy Programs

Washington, DC 20545

R. B. Chitwood

DOE Division of Nuclear Power Development

Washington, DC 20545

T. C. Chee

DOE Division of Waste Management

Washington, DC 20545

C. R. Cooley

DOE Division of Waste Management

Washington, DC 20545

C. H. George

DOE Division of Waste Management

Washington, DC 20545
No. of

Copies

C. A. Heath

DOE Division of Waste Management Washington, DC 20545

G. 0ertel

DOE Division of Waste Management Washington, DC 20545

A. F. Perge

DOE Division of Waste Management Washington, DC 20545

J. M. Taub

DOE Division of Waste Management Washington, DC 20545

D. L. Vieth

DOE Division of Waste Management Washington, DC 20545

R. D. Walton

DOE Division of Waste Management Washington, DC 20545

DOE Idaho Operations Office

PO Box 2108

Idaho Falls, ID 83401

J. J. Schreiber

DOE Oak Ridge Operations Office

PO Box $X$

Oak Ridge, TN 37830

267 DOE Technical Information Center

A. P. Roeh, Manager

Process Evaluation Branch

Allied Chemical Corporation

550 - 2nd Street

Idaho Fal1s, ID 83401

R. A. Brown

A 11 ied Chemical Corporation

550 - 2nd Street

Idaho Falls, ID 83401

C. A. Hawley

Allied Chemical Corporation

550 - 2nd Street

Idaho Falls, ID 83401

D. A. Knecht

Allied Chemical Corporation

550 - 2nd Street

Idaho Fal1s, ID 83401 
No. of

Copies

Allied Chemical Corporation

(File Copy)

550 - 2nd Street

Idaho Falls, ID 83401

J. A. Buckham

Allied-General Nuclear Services

P0 Box 847

Barnwe11, SC 29812

A. Williams

Allied-General Nuclear Services

P0 Box 847

Barnwel1, SC 29812

J. L. Jardine

Argonne National Laboratory

9700 South Cass Ave.

Argonne, IL 60439

M. J. Steindler/L. E. Trevorrow Argonne Nationa 1 Laboratory

9700 South Cass Avenue

Argonne, IL 60439

Battelle Memorial Institute 505 King Avenue

Columbu's, $\mathrm{OH} \quad 43201$

J. M. Batch

Battelle Memorial Institute

505 King Avenue

Columbus, $\mathrm{OH} 43201$

R. E. Heineman

Battelle Memorial Institute

$505 \mathrm{King}$ Ave.

Columbus, $\mathrm{OH} 43201$

2 Brookhaven National Laboratory Reference Section

Information Division

Upton, Long Island, NY 11973

Combustion Division

Combustion Engineering, Inc.

Windsor, CT 06095

2 E. Vejvoda, Director Chemical Operations

Rockwel1 International

Rocky Flats Plant

PO Box 464

Golden, C0 80401

M. D. Boersma

duPont Company, Aiken (DOE)

E. I. duPont DeNemours \& Co.

Savannah River Laboratory

Aiken, SC 29801
No. of

Copies

C. H. I ce

duPont Company, Aiken (DOE)

E. I. duPont DeNemours \& Co.

Savarınah River Laboratory

Aiken, SC 29801

A. S. Jennings

duPont Company, Aiken (DOE)

E. I. duPont DeNemours \& Co.

Savannah River Laboratory

Aiken, SC 29801

Leon Meyers

duPont Company, Aiken (DOE)

E. I. duPont DeNemours \& Co.

Savannah River Laboratory

Aiken, SC 29801

P. H. Permar

duPont Company, Aiken (DOE)

E. I. duPont DeNemours \& CO.

Savannah River Laboratory

Aiken, SC 29801

L. Henning

Electric Power Research Institute

3412 Hillview Avenue

PO Box 10412

Palo Alto, CA 94304

Environmental Protection Agency

Technology Assessment Division (AW-559)

Office of Radiation Programs

U.S. Environmental Protection Agency

Washington, DC 20460

R. G. Barnes

General Electric Company

175 Curtner Avenue

(M/C 160)

San Jose, CA 95125

L. H. Brooks

Gulf Energy and Environmental Systems

P0 Box 81608

San Diego, CA 92138

2 Central Research Library

Document Reference Section

Oak Ridge National Laboratory (DOE)

Oak Ridge, TN 37830

3 Los Alamos Scientific Laboratory

PO Box 1663

Los Alamos, NM 87544

C. J. Kershner

Monsanto Research Corporation

Mound Laboratory

PO Box 32

Miamisburg, $\mathrm{OH} 45342$ 
No. of

Copies

John Pomeroy

Technical Secretary

National Academy of Sciences

Committee of Radioactive Waste Management

National Research Council

2101 Constitution Avenue

Washington, DC 20418

2 J. P. Duckworth

Plant Manager

Nuclear Fuels Services, Inc.

PO Box 124

West Valley, NY 14171

J. G. Cline, General Manager

NYS Atomic Space and Development Authority

230 Park Avenue, Rm 2425

New York, NY 10017

D. R. Anderson

Sandia Laboratories

Albuquerque, NM 87115

W. Weart

Division 1140

Sandia Laborâtories

Albuquerque, NM 87115

J. Sivinski

Sandia Laboratories

Albuquerque, NM 87115

J. 0. Blomeke

Union Carbide Corporation (ORNL)

Chemical Technology Division

P0 Box $Y$

Oak Ridge, TN 37830

2 D. E. Ferguson

Union Carbide Corporation (ORNL)

Chemical Technology Division

PO Box $Y$

Oak Ridge, TN 37830

W. C. McClain

Union Carbide Corporation (ORNL)

Chemical Technology Division

P0 Box Y

Oak Ridge, TN 37830

C. D. Zerby

Union Carbide Corporation

Nuclear Division

PO Box Y

Oak Ridge, TN 37830
No, of

Copies

R. A. Beall

U.S. Department of Interior

Bureau of Mines

Albany Research Center

1450 W. Queen Avenue

Albany, OR 97321

R. G. Post

College of Engineering

University of Arizona

Tucson, AZ 85721

S. E. Logan

University of New Mexico

Albuquerque, NM 87131

ONSITE

4 DOE Richland Operations Office

R. B. Goranson

M. J. Shupe

D. J. Squires

M. J. Zamorski

8 Rockwell Hanford Operations

H. Batad

R. A. Deju

R. J. Gimera

E. J. Kosiancic

C. M. Manry

J. H. Roecker

D. D. Wodrich

File Copy

Exxon

Richland, WA 99352

S. J. Beard

Joint Center for Graduate Study

J. Cooper

2 United Nuclear Industries, Inc.

T. E. Dabrowski

A. E. Engler

Westinghouse Hanford Company

A. G. Blasewitz 
No. of

Copies

258 Battelle Northwest

R. P. Allen/H. W. Arrowsmith

T. W. Ambrose

N. E. Ballou

J. W. Bartlett

R. L. Brodzinski

P. G. Brown

L. L. Burger

ii. C. Burknoider

J. B. Burnham

N. E. Carter

D. B. Cearlock

T. D. Chikalla

M. O. Cloninger

R. L. Dillon

J. R. Eliason

J. W. Finnigan

J. C. Fox

J. A. Franz

J. J. Fuquay

R. W. Goles

J. A. Goodnight

B. Griggs

K. M. Harmon

A. J. Haverfield

J. A. Hébert (100)

E. R. Irish

J. H. Jarrett
No. of

Copies
J. H. Jarrett
R. S. Kemper
M. R. Kreiter
I. S. Levy
H. E. Lippek
R. C. Liikala
R. P. Marshal1
J. L. McElroy
R. W. McKee
I. C. Nelson
R. D. Nelson
J. M. Nielsen/R. W. Perkins
R. E. Nightingale
D. E. Olesen
A. M. Platt (50)
J. A. Powe 11
W. L. Rankin
C. R. Schuller
C. L. Simpson/C. E. Elderkin
R. F. Smith
G. L. Tingey
C. M. Unruh (50)
H. H. Van Tuyl
E. J. Wheelwright
D. J. Wiggins
W. R. Wiley
L. D. Williams
W. K. Winegardner
Technical Information (5) 